MISS HANNA SARAH ROSINGER (Orcid ID : 0000-0001-8453-0532)

DR. ARMANDO GERALDES (Orcid ID : 0000-0001-7239-4529)

4

5

Article type : Original Article

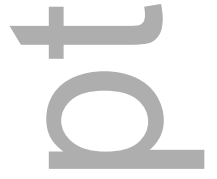

5

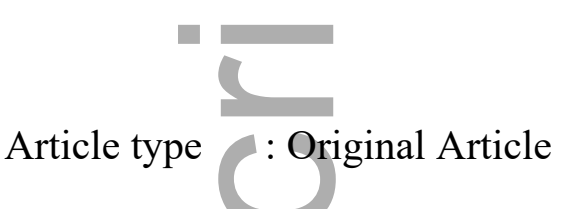

\title{
The tip of the iceberg: genome wide marker analysis reveals hidden
} hybridization during invasion

\section{Running title: Hybridization of co-invaders}

12 Hanna S. Rosinger ${ }^{1}$, Armando M. Geraldes ${ }^{2,4}$, Kristin A. Nurkowski ${ }^{1,4}$, Paul Battlay ${ }^{1}$, Roger D.

13 Cousens $^{3}$, Loren H. Rieseberg ${ }^{4}$, Kathryn A. Hodgins ${ }^{1}$

$14{ }^{1}$ School of Biological Sciences, Monash University, Melbourne, VIC, Australia

15 2Department of Zoology, University of British Columbia, Vancouver, BC, Canada,

$16{ }^{3}$ School of BioSciences, University of Melbourne, Melbourne, VIC, Australia

$17{ }^{4}$ Department of Botany and Biodiversity Research Centre, University of British Columbia,

18 Vancouver, BC, Canada

This is the author manuscript accepted for publication and has undergone full peer review but has not been through the copyediting, typesetting, pagination and proofreading process, which may lead to differences between this version and the Version of Record. Please cite this article as doi: $\underline{10.1111 / M E C .15768}$

This article is protected by copyright. All rights reserved 
* Correspondence:

Hanna S. Rosinger

21 Hanna.Rosinger@monash.edu

22 Abstract

23 Biological invasions are accelerating, and invasive species can have large economic impacts as well as severe consequences for biodiversity. During invasions, species can interact, potentially resulting in hybridization. Here, we examined two Cakile species, C. edentula and C. maritima (Brassicaceae), that co-occur and may hybridize during range expansion in separate regions of the globe. Cakile edentula invaded each location first, while C. maritima established later, apparently replacing the former. We assessed the evidence for hybridization in western North America and Australia, where both species have been introduced, and identified source populations with 4561 SNPs using Genotype-by-Sequencing. Our results indicate that $C$. edentula in Australia originated from one region of eastern North America while in western North America it is likely from multiple sources. Cakile maritima in Australia is derived from at least two different parts of Europe while the introduction in western North America is from one. Although morphological evidence of hybridization is generally limited to mixed species populations in Australia and virtually absent elsewhere, our genetic analysis revealed relatively high levels of hybridization in Australia (58\% hybrids using Admixture) and supported the presence of hybrids in western North America (16\% hybrids using Admixture) and New Zealand. Hybrids might be commonly overlooked in invaders, as identification based solely on morphological traits may represent only the tip of the iceberg. Our study reveals a repeated pattern of invasion, hybridization and apparent replacement of one species by another, which offers an opportunity to investigate the role of hybridization and introgression during invasion.

Keywords: invasion, hybridization, Cakile edentula, Cakile maritima, Genotype-by-Sequencing

\section{(GBS), range expansion}

\section{$44 \quad 1$ Introduction}

45 Biogeographic barriers on a global, regional and local scale are often overcome by human activities, 46 leading to biological invasions (Sax \& Gaines, 2003; Simberloff, 2013; Vilatersana, Sanz, Galian, \& 47 Castells, 2016). Biological invasions can have a large economic impact (Hoffmann \& Broadhurst, 48 2016; Pimentel, Zuniga, \& Morrison, 2005), as well as severe negative consequences for biodiversity 
and ecosystems (Sakai et al., 2001). Most long-distance introductions of invasive species in historic times are directly (e.g. ornamentals) or indirectly the result of anthropogenic activities (e.g. via ballast on ships) (Baker, 1974; Ruiz et al., 2000; Sakai et al., 2001). Invasions can also lead to novel interactions between species that previously had not co-occurred and, where there are no strong reproductive barriers, this may lead to instances of hybridization (Abbott, 1992; Ellstrand \& Schierenbeck, 2000, Vallejo- Marín \& Hiscock, 2016).

Rather than hybridization just being an incidental event, it could actually facilitate the success of invasive plant species, as invasive hybrid lineages can have increased fecundity and size (Hovick \& Whitney, 2014). Various hypotheses have been proposed by which hybridization facilitates rapid range expansion (Bock et al., 2015; Ellstrand \& Schierenbeck, 2000), including evolutionary novelty, increased genetic variation, heterosis, dumping genetic load (i.e. genetic rescue) (Ellstrand \& Schierenbeck, 2000) and demographic rescue (Mesgaran et al., 2016). But convincing empirical data are limited. Hybridization is certainly not the sole evolutionary pathway to invasiveness, but can catalyze its evolution (Ellstrand \& Schierenbeck, 2000). Not all of the potential consequences of hybridization are beneficial, however, and there can be significant costs associated with the phenomenon, such as outbreeding depression (Baack, Melo, Rieseberg, \& Ortiz-Barrientos, 2015) and genetic swamping (Todesco et al., 2016). Our capacity to assess the role of hybridization during any particular invasion is hampered by the fact that it can be difficult to identify, especially when repeated backcrossing with one parental species has occurred rendering morphological identification difficult (Ward, Gaskin, \& Wilson, 2008). However, genome-wide molecular markers can provide estimates of the extent of past hybridization and introgression across the genome (Payseur \& Rieseberg, 2016).

On the beaches of Australia, the North Island of New Zealand and western North America a repeated pattern of invasion by two species of sea-rocket with contrasting mating systems (Barbour \& Rodman, 1970; Cousens, Ades, Mesgaran, \& Ohadi, 2013; Cousens \& Cousens, 2011; Rodman, 1974, 1986) offers a rare opportunity to investigate the role of hybridization during invasion in distinct, geographically isolated regions. Cakile edentula (American sea-rocket), native to eastern North America, invaded each location first, while Cakile maritima (European sea-rocket) (Brassicaceae), native to Europe and northern Africa, arrived later. The invasion and replacement history in western North America and Australia are reviewed elsewhere (Barbour \& Rodman, 1970; Cousens et al., 2013; Rodman, 1986), but we briefly outline it below. 
In Australia, C. edentula was first recorded in Victoria in 1863 and subsequently spread along the coastline of Australia (Rodman, 1986). In 1897, C. maritima was recorded for the first time in Western Australia, and a second introduction into South Australia (1918: see Cousens et al., 2013; Ohadi et al., 2016) spread from there to the east (Heyligers, 1984; Rodman, 1986). In contrast to $C$. edentula, C. maritima seems still to be actively spreading in Australia and appears to have replaced C. edentula throughout much of its initial introduced range (Cousenes et al., 2013; Rodman, 1986). In western North America, a similar pattern of replacement occurred. Cakile edentula was found near San Francisco around 1880 (Barbour \& Rodman, 1970), while C. maritima reached western North America by 1935 where it was found sympatric with C. edentula near San Francisco. The most recent published field study showed that C. maritima had replaced C. edentula throughout most of coastal California but not Oregon or Washington (Boyd \& Barbour, 1993). In each case, there has been complete replacement of $C$. edentula by C. maritima over wide geographic areas (Barbour \& Rodman, 1970; Cousens et al., 2013; Rodman, 1986), which was originally assumed to involve either direct or indirect competition (Rodman, 1986), although several additional mechanisms have been proposed such as disease (Bock, 2008; Cousens et al., 2013; Thrall, Young, \& Burdon, 2000), coincidence (Cousens et al., 2013; Rodman, 1986), or greater lifetime fecundity of C. maritima (Boyd \& Barbour, 1993). However, the mechanism of the replacement remains unclear.

Cakile edentula and C. maritima are closely related and cross-compatible (Li, Cousens, \& Mesgaran, 2019; Mesgaran et al., 2016; Rodman, 1974). Both species are found in coastal strandline habitat, providing opportunities for hybridization in regions where they co-occur, but the species exhibit contrasting mating systems (Rodman, 1974). Cakile edentula (self-compatible) benefits from high levels of reproductive assurance as it is able to set seeds autonomously at high rates ( $\mathrm{Li}$, Mesgaran, Ades, \& Cousens, 2020); one of Baker's (1965) ideal weed traits. In contrast, the establishment of $C$. maritima (self-incompatible) may be initially hindered (during both initial establishment as well as subsequent range expansion) by a lack of compatible mates limiting sexual reproduction and resulting in strong Allee effects. The apparent presence of hybrids, based on an intermediate leaf and fruit shape of both parental species, in some sites in Australia led Mesgaran et al., (2016) to develop a model for the interacting species, with the novel outcome that transient hybridization could overcome Allee effects in C. maritima. As a consequence, we hypothesized that past hybridization with $C$. edentula could be a common feature of C. maritima's establishment and range expansion in western North America, Australia and New Zealand. 
111 We used genome-wide markers derived from Genotype-by-Sequencing (GBS) to examine the

112 invasion history of these two species in Australia and western North America and quantify the extent

113 and distribution of hybridization. There have been several previous studies examining the population

114 genetic structure of C. edentula and C. maritima in their native ranges in Europe (Clausing, Vickers,

115 Kadereit, 2000; Kadereit, Arafeh, Somogyi, \& Westberg, 2005; Westberg, 2005), Africa (Gandour,

116 Hessini, \& Abdelly, 2008), eastern and western North America (Gormally, Hamrick, \& Donovan,

117 2011) as well as in the introduced range of Australia (Ohadi et al., 2016). However, no study of the

118 invasion history on two continents has been attempted nor has the extent of hybridization across

119 multiple introductions been quantified. Specifically, we aimed to (1) identify probable source regions

120 (from Europe and eastern North America); (2) determine whether both recent and advanced

121 generation hybrids occur in the introduced ranges and the extent of their geographic distribution; and

122 (3) determine if the change in levels of species ancestry post-invasion reflects a chronosequence

123 along the direction of invasion of C. maritima. We predicted that early generation hybrids should be

124 present at the leading edge of $C$. maritima's invasion into C. edentula-occupied areas, but later

125 generation backcrosses with $C$. maritima should be more common in areas closer to where $C$.

126 maritima first established. This should contribute to a gradient in species ancestry whereby $C$.

127 maritima ancestry will be dominant in hybrids near the invasion source, while C. edentula ancestry

128 will be more prevalent in hybrids identified in areas recently invaded by C. maritima. We predicted

129 high levels of $C$. maritima ancestry in hybrids near the invasion source because C. maritima

130 phenotypes are now exclusively present in the regions surrounding the invasion source, and studies

131 of pollinators suggest preferential visitation of both hybrids and C. maritima over C. edentula which

132 should facilitate backcrossing to C. maritima (Mesgaran et al., 2016).

\section{Methods}

\section{$134 \quad 2.1 \quad$ Study species}

135 Cakile maritima's native range extends over a wide climatic range from northern Norway to northern 136 Africa. Current taxonomy recognizes subsp. maritima (Mediterranean), subsp. baltica (Baltic), subsp. 137 integrifolia (Atlantic coast), subsp. islandica (Northern Europe and Northwestern Russia) and subsp. 138 euxina (Black Sea) (Marhold, 2011). This is paralleled in the western Atlantic by C. edentula, for 139 which two subspecies are recognized in its native range (Rodman, 1974) subsp. edentula (Labrador 140 to North Carolina) and subsp. harperi (North Carolina to Florida). Although C. maritima has a 141 sporophytic self-incompatibility system, the level of self-incompatibility varies among plants (Thrall 
142 et al., 2000). Cakile edentula is self-compatible and can set seed autonomously at a high rate

143 (Barbour, 1970; Rodman, 1974), although field estimates are suggestive of intermediate levels of 144 autonomous selfing ( $\mathrm{Li}$ et al., 2020). Both species are diploid $(2 n=18)$ (Rodman, 1974). Hybrids are 145 readily produced through artificial pollination (Rodman, 1974) with either parent as the pollen donor 146 when emasculated(Li et al., 2019; Mesgaran et al., 2016), although crosses are more successful when 147 C. edentula acts as the pollen recipient, consistent with the SI x SC rule (Harrison \& Darby, 1955).

\subsection{Samples}

150 Samples of Cakile spp. were obtained from the native ranges (Europe and northern Africa, eastern 151 North America) and the two introduced ranges (Australasia, western North America). We collected 152 four of the five subspecies (subsp. baltica, subsp. maritima, subsp. integrifolia and subsp. islandica) 153 of $C$. maritima. In the native range of $C$. edentula we sampled only $C$. edentula subsp. edentula as 154 this subspecies is most likely the source of invasions in Australia and western North America 155 (Cousens et al., 2013; Rodman, 1974). We obtained 214 samples of C. maritima, 137 samples of $C$. edentula, 17 putative hybrids (identified by morphology in the field) and two C. lanceolata samples 157 from 92 locations in total (Figure S1; Table $1 \&$ S1). Most samples were our own field collections of 158 silica dried leaf tissue although a few samples were purified DNA from colleagues. We collected our samples along a transect through a population, ensuring that individuals were at least $2 \mathrm{~m}$ apart to avoid sampling close relatives or the same individual and collected individuals randomly with respect to their putative species based on morphology.

\subsection{DNA extraction and Genotype-by-sequencing}

164 We performed DNA extractions from dried leaf material using a modified CCDB DNA Extraction 165 Protocol following Whitlock, Hipperson, Mannarelli, and Burke (2008). DNA quantity was assessed 166 using a QuBit broad-sensitivity DNA quantification system (Invitrogen, Carlsbad, CA, USA) and a double-digest GBS library preparation was carried out (using PstI-HF (NEB) and MspI (NEB) enzymes, see Supplementary Information for details). Sequencing (125bp PE) was conducted on an Illumina HiSeq2500 (McGill University and Genome Quebec Innovation Centre) on two lanes. 


\subsection{SNP calling}

172 Quality statistics of raw reads were assessed though FastQC (http://hannonlab.cshl.edu/fastx_toolkit) 173 and the reads were demultiplexed using STACKS process_radtags (Catchen, Amores, Hohenlohe,

174 Cresco, \& Postlethwait, 2011). We removed adapter sequences and trimmed the reads using Sickle 175 (Joshi \& Fass, 2011) with a Q-score of $\geq 20$ and read length of $\geq 20$ base pair. FASTQ quality filter 176 (http://hannonlab.cshl.edu/fastx_toolkit) was then used to filter for reads with a Q- score of 20 or 177 greater for $\geq 90 \%$ of the read length. The filtered reads were aligned using the Burrows-Wheeler 178 Aligner (BWA) (Li \& Durbin, 2009) to a C. maritima draft genome. Early access to the draft genome 179 was provided by S.I. Wright, University of Toronto 180 (https://genome.jgi.doe.gov/portal/CakmarStandDraft/CakmarStandDraft.info.html, GenBank: 181 MK637688.1). The reference genome is found in 26,153 scaffolds with a scaffold N50 of 85,425. We 182 assessed if there was a bias when mapping the reads of $C$. edentula to the reference genome of $C$. 183 maritima but found limited evidence for such a bias (see Supplementary Information, Figure S2 \& 184 S3).

We called variants with GATK HaplotypeCaller (Poplin et al., 2017). We refer to this as the unfiltered dataset (Rosinger et al., 2020). Using VCFtools (Danecek et al., 2011) we removed individuals with fewer than 25000 reads, removed indels and restricted individual genotypes to have a depth between 5-100,000. Furthermore, we filtered for a minimum quality score of 20, a genotype quality of 20, and a minor allele frequency of 0.05 . Subsequently, we kept only bi-allelic variants that were successfully genotyped in more than $50 \%$ of individuals and removed individuals that had more than 50\% missing data. The above filtering steps resulted in 18,573 SNPs from 258 individuals. Additionally, we removed 121 SNPs which showed $>80 \%$ observed heterozygosity, because such

194 high observed heterozygosity could be caused by paralogues. We refer to this as the filtered dataset

195 (Rosinger et al., 2020), which had a mean coverage of 39.21 (minimum coverage 9.18, maximum 196 coverage 504.73).

\subsection{Genetic clustering}


199 Population genetic structure was inferred using Admixture (Alexander, Novembre, \& Lange, 2009).

200 For Admixture and most of our analysis we thinned our filtered dataset for linkage using a single

201 SNP per $1 \mathrm{~kb}$ window, resulting in a reduction to 4561 SNPs from 257 individuals (excluding the

202 outgroup C. lanceolata). We will refer to this as the global thinned dataset. We ran Admixture using

203 the global thinned dataset with a major termination criterion of $1 \times 10^{-9}, 1000$ bootstraps and ten-fold

204 cross-validation for $\mathrm{K}=1-10$, where $\mathrm{K}$ equals the number of genetic groups. The $\mathrm{K}$ that produced the

205 lowest cross-validation error was selected as the best $\mathrm{K}$ value. We refer to this as the unsupervised

206 run. All following analyses were conducted in R v.3.5.2 (R Core team, 2018) except where otherwise

207 stated. The output of Admixture visualized with pophelper v.2.3.0 (Francis, 2017) and pie charts.

208 To complement the population clustering analysis and to provide further insight in the population

209 differentiation, we conducted a principal component analysis (PCA) and an unrooted phylogenetic

210 network analysis. Genetic differentiation between native and introduced populations was summarized

211 in a PCA with an 95\% confidence ellipse using the R package SNPRelate (Zheng et al., 2012),

212 tidyverse (Wickham, Francois, Henry, \& Müller, 2019) and car (Fox \& Weisberg, 2019) on the

213 global thinned dataset. We used SPLITSTREE5 (Huson \& Bryant, 2006) to visualize the overall

214 sample relatedness with an unrooted phylogenetic network. To do this, we created two datasets from

215 our unfiltered dataset (see details in Supplementary Information); (1) a global dataset containing all

216 samples (global Splitstree dataset) and (2) a native range dataset containing samples from Europe

217 and eastern North America (native range Splitstree dataset).

\subsection{Hybrid identification}

220 We used three different approaches to identify hybrids using genetic data:

221 (1) A supervised run of Admixture for $\mathrm{K}=2$ using the global thinned dataset, by setting the samples

222 from the two native ranges as reference individuals. Providing known ancestries allows the program

223 to set some rows in the matrix Q to known constants and provides a more accurate estimation of the 224 ancestries of the remaining individuals, and of the ancestral allele frequencies (Alexander et al., 225 2009). The other settings were retained from the unsupervised run. We refer to this as the supervised 226 run and used this run to classify individuals by their Q-scores as hybrid, or pure species. We used the 227 highest standard error from the Q scores, resulting in individuals classified as hybrids if $0.025<\mathrm{Q}>$ 2280.975 of their genome was assigned to the C. edentula cluster.

This article is protected by copyright. All rights reserved 
229 (2) We used the program NewHybrids (Anderson \& Thompson, 2002) to identify early generation 230 hybrids. It classifies their generation using a Bayesian model-based clustering framework to 231 compute, by Markov chain Monte Carlo, the posterior probability that each individual belongs to 232 each of the distinct first two generation hybrid classes (parental species, F1, F2, BC to species 1, BC 233 to species 2). As the program is unable to deal with a large dataset, we restricted our data to 63 SNPs 234 that showed fixed differences between the two species obtained from individuals classified as 235 parental species using the supervised run of Admixture. Details of the settings used are provided in 236 the Supplementary Information.

237 (3) We used the R package HIest (Fitzpatrick, 2012), which uses maximum likelihood to estimate 238 ancestry and heterozygosity. For this package, we used the 471 loci that showed fixed differences 239 between the individuals of the native ranges. Because it is possible that there is a low level of 240 segregating variation within each species for these loci due to sampling error, particularly for SI $C$. 241 maritima where the sample size is lower, we set the allele frequencies as 0.99 for $C$. edentula and 2420.03 for $C$ maritima. We also tested other SNP sets and allele frequencies. The details of the settings 243 used and the hybrid assignments along with the results are provided in the Supplementary 244 Information.

245 We tested for a chronosequence by assessing if there was a correlation between the distance of each 246 population from the first entry point of C. maritima (Adelaide in Australia, San Francisco in western 247 North America) and the level of $C$. maritima and C. edentula ancestry using a Spearman's rank 248 correlation test in $\mathrm{R}$ using the ggpubr package (Kassambara, 2020). We used the ranked order of 249 populations from this origin point along the coastline for each range. In Australia, we only used the 250 south-east mainland individuals (see Supplementary Information for details). We tested the 251 correlation between the $\mathrm{Q}$ value of the $C$. edentula cluster of the supervised run for each population 252 and the rank order of the sampling locations along the coastline to the first entry point of $C$. 253 maritima. We used individuals that were classified as hybrids by Admixture or all samples (including the parental species). We repeated this analysis using the $\mathrm{S}$ value from HIest and the hybrid classifications of this program.

Additionally, we used the program TreeMix (Pickrell \& Pritchard, 2012) to identify evidence for hybridization in the introduced ranges using the global thinned dataset for which we constructed maximum likelihood trees and calculated the $f_{3}$ statistic (for details see Supplementary Information). 


\subsection{Genetic diversity and differentiation}

261 Genetic diversity and differentiation within the two native ranges and two introduced ranges were

262 assessed for the 256 individuals (the New Zealand and C. lanceolata samples were excluded) using 263 the global thinned dataset. We calculated observed heterozygosity $\left(\mathrm{H}_{\mathrm{O}}\right)$ and allelic richness $\left(\mathrm{A}_{\mathrm{R}}\right)$ 264 with the diveRsity package (Keenan, McGinnity, Cross, Crozier, \& Prodöhl, 2013). The 95\% 265 confidence intervals of $A_{R}$ were calculated with 1000 bootstraps. We estimated differences in genetic 266 diversity between the species and ranges because we expected self-fertilization in C. edentula and 267 bottlenecks potentially experienced during introduction would reduce diversity. Because sampling at 268 individual locations was limited in the native ranges, we grouped individuals based on their range, 269 and their hybrid ancestry (pure parental or hybrid) using the supervised run Q-value assignments of the global thinned dataset into eight groups. We used the Q value assignment of the C. edentula cluster and the highest standard error (0.024) of the supervised run to classify individuals. To determine regional differentiation we calculated Weir and Cockerham's (1984) pairwise $\mathrm{F}_{\mathrm{ST}}$ between the above eight groups using the global thinned dataset with VCFtools (Danecek et al., 2011). Additionally, we calculated the $\mathrm{F}_{\mathrm{ST}}$ for pure parental individuals, grouping individuals according to their Admixture cluster from the unsupervised run and range (see Supplementary Information).

\section{$3 \quad$ Results}

\subsection{Genetic structuring and differentiation}

279 The Admixture analysis of the unsupervised run showed genetic structuring of C. maritima, C. 280 edentula and hybrids with an optimal K value of 8 (Figure 1 A, B \& S4). Genetic structure was 281 present in the native range of $C$. edentula, where single samples from Lake Michigan and Rhode 282 Island constituted one group, samples from New Brunswick within the Gulf of St. Lawrence a second 283 group, samples from Newfoundland and Quebec (along the St Lawrence River) a third group and samples from Nova Scotia a final group. As expected, for C. maritima, there were two main groups: one group was largely from the Baltic and Atlantic coasts, which we term the "Atlantic" group (comprising mainly the dark blue cluster, Figure 1 A, B) and a second admixed group was associated 
medium blue clusters, Figure 1 A, B). In Australia, several genetic clusters were identified. First, in Queensland, New South Wales and Tasmania we identified pure C. edentula individuals. Second, for populations along the west coast of Australia, we identified a $C$. maritima cluster associated with the Atlantic coast in the native range. Third, in South Australia, genetic clusters associated with the Mediterranean were found. In the south-east of Australia there was evidence of hybrids between $C$. maritima and C. edentula (see below). In the introduced range of western North America, we identified pure $C$. edentula along with pure $C$. maritima (Figure $1 \mathrm{~A}, \mathrm{~B}$ ). A small number of samples from Washington, Oregon and California showed evidence of hybridization (see below).

The PCA and SPLITSTREE5 analyses confirmed the findings of Admixture. There was clear differentiation of $C$. maritima and $C$. edentula in the global thinned dataset. The first eigenvector (EV) (Figure 2 A \& S5 A) explained $33.17 \%$ of the variation and clearly delineated the species. The $C$. edentula group showed less variation than the $C$. maritima group along the first two EVs. Two $C$. maritima groupings were also evident with one representing C. maritima from Europe and Australia $(\mathrm{EV} 1<0, \mathrm{EV} 2<0)$ and the other representing exclusively C. maritima from western North America $(\mathrm{EV} 1<0, \mathrm{EV} 2>0)$. In the SPLITSTREE5 network, using the global Splitstree dataset, C. edentula (as identified by the supervised run) formed a monophyletic group without admixture. C. maritima samples were split into three groups (Figure 2 B, C): C. maritima (Mediterranean group), $C$. maritima (Atlantic group) and C. maritima in western North America. Hybrids of the two species were scattered in between the $C$. maritima groups or between the two-parental species along the network. The additional native range SPLITSTREE5 analysis (Figure S6) mirrored this pattern but provides clearer C. edentula grouping in the native range.

Pairwise $\mathrm{F}_{\mathrm{ST}}$ (Table S2) using the global thinned dataset revealed clear genetic differentiation between the two-parental species originating from the native range $\left(\mathrm{F}_{\mathrm{ST}}>0.527\right)$. Within the introduced ranges the pairwise $\mathrm{F}_{\mathrm{ST}}$ between the two species was similar to the comparison of the native ranges. Hybrids identified using Admixture in the introduced ranges showed higher genetic differentiation from C. edentula than from C. maritima (Table S2).

\subsection{Genetic diversity}

316 Population statistics revealed that in their native ranges, $C$. edentula, the self-compatible species, has

317 considerably less $\mathrm{H}_{\mathrm{O}}$ than $C$. maritima and the hybrids of the two species (Table S3). $A_{R}$ was 
318 significantly reduced in $C$. edentula in comparison to $C$. maritima, the largely self-incompatible 319 species. In the introduced ranges, no clear reduction of $H_{O}$ or $A_{R}$ was observed in either of the 320 species. Hybrids of the two-species had higher $\mathrm{H}_{\mathrm{O}}$ and $\mathrm{A}_{\mathrm{R}}$ compared to both parental species.

321

322

\subsection{Hybrid classification}

323 The three approaches classified different proportions of individuals as hybrids, as expected due to 324 their ability to detect recent hybrids (NewHybrid, HIest), versus hybrid ancestry (Admixture, HIest). 325 All hybrids identified by NewHybrids were also identified as hybrids with HIest and Admixture 326 (Table S4 \& S5). The fourteen putative hybrids included in the samples as a result of morphological 327 identification were assigned by all analyses as hybrids, providing evidence of the accuracy of the

328 assignments. Furthermore, the NewHybrid analysis confirmed that these hybrids were likely the 329 product of the first two generations of interbreeding. NewHybrids analysis revealed 19 hybrids 330 (Figure 3; Table S4) with 17 hybrids in Australia (13.49\%), one in western North America (1.47\%) 331 and one in New Zealand. In Australia, F1 and F2 hybrids were detected in the current sympatric 332 zones where individuals with both species' phenotypic traits were clearly identifiable in the

333 populations. Hybrids (Figure S5 B) grouped in the PCA according to their generation, with F1 and F2

334 hybrids grouped between the parental species, and backcrosses grouped closer to species they 335 backcrossed to. In this same PCA the advanced generation hybrids identified with the supervised run 336 of Admixture as well as HIest frequently grouped with C. maritima, suggestive of further 337 backcrossing to that species.

338 Classification of hybrids using the supervised run of Admixture revealed 73 hybrids in Australia 339 (57.94\%) from 15 locations, 11 hybrids in western North America (16.18\%) from five locations and 340 one hybrid from New Zealand (Figure 1; Table S4). In western North America hybrids were found in 341 each of two locations in California and Oregon and in one location in Washington.

342 All Admixture hybrids were also identified as hybrids in HIest and the ancestry assignments were 343 highly correlated between the programs (Figure S7). When the 471 loci that are fixed between native 344 range samples were used, and we allowed for a low level of polymorphism within each species $(0.99$ 345 C. edentula, 0.03 C. maritima), a larger number of hybrids were identified using HIest than 346 Admixture (138 versus 85, Table S6). Changing the allele frequencies and SNP set impacted the 347 number of hybrids identified (see Supplementary Information), but this only influenced the 
classification of individuals with an apparent low level of ancestry from the alternate species. In all the runs, advanced generation hybrids were identified in this analysis with many in regions where $C$. maritima has not been recorded for many decades, but also in the current sympatric zone (New South Wales, Queensland and Tasmania).

We then examined if patterns of ancestry in Australia and western North America reflected the likely invasion route of C. maritima. Specifically, we tested if low levels of $C$. edentula ancestry were found in areas where $C$. maritima first arrived, and if high levels of $C$. edentula ancestry were found in regions $C$. maritima has more recently invaded and where $C$. edentula is still present. Using the supervised Admixture analysis, the mean $C$. edentula ancestry of hybrids at each location was correlated with the ranked distance from where C. maritima first arrived in south-eastern mainland Australia $(\rho=0.82, p<0.01)$ (Table 2). This pattern was also significant when testing across all samples, including individuals identified as parental species $(\rho=0.89, p<0.05)$. However, in western North America, although the direction of the correlation was as predicted, a geographic pattern in ancestry was only significant when using locations north of San Francisco as well as parental and hybrid individuals $(\rho=0.72, \mathrm{p}<0.05)$. The same pattern of significance was found when using the results of the HIest (Figure $4 \& 5 \&$ S8; Table 2).

364 We used TreeMix to assess geneflow between C. edentula and C. maritima within each introduced range. The maximum likelihood tree in both invasive ranges showed bidirectional gene flow (Figure

6). In Australia geneflow occurred from the C. edentula branch into Australian C. maritima (Mediterranean); a migration event also occurred from this group into the $C$. edentula branch (Figure $6 \mathrm{~B})$. In western North America the same pattern occurs. There is evidence of a migration event from the $C$. edentula branch into western North American $C$. maritima as well as a migration event from the western North American C. maritima branch into the western North American C. edentula (Figure $6 \mathrm{~A}$ ). The $f_{3}$ statistic of TreeMix (Table 3) confirmed that the hybrids (identified by the supervised Admixture run) in the introduced range are admixed from the $C$. edentula and $C$. maritima parental individuals within both introduced ranges (Australia $f_{3}=-0.006, Z=-31.97$; western North America $\left.f_{3}=-0.005, Z=-23.22\right)$.

\section{Discussion}


377 Our analysis sheds light on the origin and extent of hybridization of two introduced species in two

378 separate invasions, which experienced a parallel pattern of invasion and apparent replacement of one

379 species by another. Except at places where the two species are currently sympatric and new hybrids

380 are still being formed, it would be difficult to determine morphologically that hybridization has ever

381 taken place, since backcrossing soon hides its phenotypic evidence. Cakile maritima is highly

382 variable within and between populations in its native range and hybrids in the introduced range could

383 easily be overlooked (e.g. Cousens et al., 2013) without the use of molecular methods. However, our

384 analysis identified extensive hybrid ancestry in the introductions, particularly in Australia. It is

385 therefore an intriguing possibility that hybridization may be commonly overlooked in a much wider

386 range of invasive taxa, especially where morphological trait indicators of hybridization are more

387 cryptic. Alien floras commonly include many congeneric species whose capacity for interbreeding is

388 yet to be established. While previous authors (Ellstrand \& Schierenbeck, 2000) have raised our

389 attention to obvious hybrid species and allopolyploids, perhaps the impacts of hybridization are often

390 more insidious. It is thus important - though not an easy task - to determine in future the extent to

391 which such non-apparent introgression has been beneficial during invasion.

\section{$392 \quad 4.1 \quad$ Native range patterns}

393 One of our primary goals was to identify the source regions for the invasions for each species and our analysis provided evidence of geographic structuring in the $C$. edentula native range, at a much finer grain than currently recognized taxonomically (Figure 1). Samples from Quebec, Newfoundland, Nova Scotia and New Brunswick contain separate Admixture clusters, likely within C. edentula subsp. edentula var. edentula as this subspecies is the only one described in this region of the North American Atlantic coast (Rodman, 1974). Two single samples from Lake Michigan and Rhode Island grouped together in one cluster of the Admixture analysis; those samples might belong to the Atlantic coast variety of $C$. edentula subsp. edentula var. edentula as it is known to have invaded Lake Michigan in historical times (Huebner, 2009; Rodman, 1974), where it now coexists with the Great Lakes endemic var. lacustris. A second possibility, suggested by Gormally et al., (2011), but without morphological evidence, is that var. lacustris has dispersed to the Atlantic. Genetically distinct regional variation is not surprising, as the directions of currents and the influences of geological features on seed dispersal can be highly predictable (Lapointe, 2000). Similar conclusions have been reached in the Mediterranean by Westberg (2005) and Gandour et al. (2008). Cakile edentula subsp. harperi occurs in areas south of the populations sampled in our study (Rodman, 1974), but comprehensive studies of herbarium samples by Rodman (1974) and Cousens et al., 
(2013) have found no morphological evidence that subsp. harperi has been introduced anywhere outside its native range.

411 Our analyses revealed clustering of C. maritima in its native Europe largely consistent with the 412 accepted taxonomic distributions (Ball, 1964; Marhold, 2011; Rodman, 1974) as well as one previous

413 population genetic analysis (Clausing et al., 2000). Other genetic studies with greater sampling 414 intensity, however, showed more differentiation on a local level (Kadereit et al., 2005; Westberg, 415 2005). The absence of fine-grain local differentiation in our study might be driven by the limited 416 number of native range samples for this species and restricted sampling of the Baltic area.

417 Cakile edentula showed lower genetic diversity than C. maritima in their native ranges as measured 418 by $A_{R}$ and $H_{O}$ (Table $S 3$ ) and showed less variation along the EVs and in the SPLITSTREE network 419 analysis (Figure 2). Higher selfing rates in C. edentula would be expected to reduce the effective 420 population size compared to the largely self-incompatible C. maritima (Pollak, 1987).

\section{$421 \quad 4.2 \quad$ Introduced range patterns}

\section{4.2.1 Australia and New Zealand}

423 Although C. edentula has now disappeared from much of its original introduced range in Australia, 424 some pure C. edentula populations still remain. Our analyses show that they likely originate from 425 populations located in Nova Scotia as they contained an Admixture cluster found exclusively in this region of the native range and showed the lowest genetic differentiation from this region (Figure 1; Table S7). Cakile edentula's $\mathrm{A}_{\mathrm{R}}$ and $\mathrm{H}_{\mathrm{O}}$ did not change considerably in Australia compared to the native range (Table S3), which is inconsistent with a strong invasion bottleneck. The genetic structure of the Australian C. maritima samples is consistent with a history of multiple introductions. This is in accordance with previous morphological and genetic studies of invasion history in Australia (Cousens et al., 2013; Ohadi et al., 2016; Rodman, 1976, 1986). In particular, the cluster associated with the Atlantic European group is found in western Australia, while a Mediterranean cluster predominates in southern and eastern Australia (Figure 1; Table S8). Similarly, analysis of microsatellite markers indicated that that western and south-eastern populations of C. maritima in Australia were genetically distinct and most likely resulted from independent introductions with severely limited gene flow from west to east (Ohadi et al., 2016). Finally, Australian C. maritima showed higher $A_{R}$ and $H_{O}$ values than its native range, consistent with admixture of multiple source populations and/or hybridization with C. edentula. Many successful invasions are sourced from

This article is protected by copyright. All rights reserved 
multiple introductions (e.g., Vallejo- Marín et al., 2020; van Boheemen et al. 2017) and both

440 hybridization and multiple introductions and admixture may spur successful invasions (Ellstrand \&

441 Schierenbeck, 2006; Dlugosch \& Parker, 2008; Hodgins, Bock, Rieseberg, 2018).

442 Our data provides substantial evidence for extensive hybridization in Australia between the two 443 species. TreeMix supported bidirectional gene flow between the parental species (identified 444 morphologically) (Figure 6). This was confirmed by the Admixture global analysis (Figure 1), the 445 PCA and Splitstree analysis, as many Australian samples fell in-between the native range samples of 446 both species (Figure 2), and the $f_{3}$ test (Table 3). Further support is provided by three separate 447 analyses which specifically detect hybrid individuals (Figure 1 \& 3 \& 4 \& 5 \& S8; Table S4). As expected, Australian hybrids (supervised Admixture run) had higher genetic diversity than both parental species (Table S3). Furthermore, the pattern of hybrid ancestry was geographically structured and reflected the historical invasion route of $C$. maritima in south-eastern Australia. This pattern was consistent across two separate approaches (supervised Admixture run, HIest) to identify hybrid ancestry (Figure $1 \& 4$; Table 2). NewHybrids confirmed the presence of a small number of early generation hybrids (within two generations) where both species still co-occur and some mixed populations show pure genotypes of both parental species and early generation hybrids, demonstrating on-going hybridization of the two taxa (Figure 3). In areas where C. edentula still persists, backerossing to $C$. edentula has also occurred, but is rare, and recent backcrosses to $C$. maritima appear to be more common. In those parts of Australia where $C$. maritima has already appeared to have replaced $C$. edentula (i.e., where no $C$. edentula phenotypes remain; Cousens et al., 2013; Rodman, 1986), evidence is consistent with past hybridization between the species and repeated backcrossing to $C$. maritima (Figure $1 \& 4 \& 6$ ). In areas of Western Australia, where $C$. edentula has never been identified, evidence of hybridization with $C$. edentula was also found, confirming a previous observation by Ohadi et al., (2016). The sample from New Zealand was

463 identified as a hybrid where the same replacement of $C$. edentula by C. maritima has also taken place 464 (Cousens \& Cousens, 2011).

\subsubsection{Western North America}

466 Our results revealed that $C$. edentula in western North America most likely originated from two 467 sources in eastern North America. We also found that western North American C. maritima 468 potentially originated from the Mediterranean region, as C. maritima in western North America 469 contained the same Admixture clusters as the Mediterranean and showed the lowest differentiation 
from this region (Figure 1; Table S7 \& S8). However, these populations were genetically distinct (Figure $2 \&$ S5) suggesting the possibility of an unknown source for this invasion, or the impact of an invasion bottleneck. Cakile edentula and C. maritima in western North America showed, as in Australia, no reduction of $\mathrm{H}_{\mathrm{O}}$ and $\mathrm{A}_{\mathrm{R}}$, which may reflect the impacts of undetected hybridization, large founding populations, or multiple introductions.

Like Australia, hybridization was identified between the two species in western North America, although the proportion of hybrids was less (e.g., 58\% versus 16\% using the supervised Admixture run). TreeMix identified bidirectional gene flow between the species in western North America (Figure 6; Table 3), and evidence consistent with hybridization was apparent in the global Admixture analysis (Figure 1), the PCA and Splitstree analysis (Figure 2). Furthermore, we employed three independent methods to specifically identify hybrid individuals and their likely generation. From this we identified 11 hybrid samples (all 11 were identified by both HIest and Admixture and one as an F2 by NewHybrids) from five locations in western North America. Specimens of hybrids based on morphological identification are largely unknown for this region, either in herbaria or in the field (Rodman, 1974). But more recently, Cody and Cody (2004) reported a small percentage of hybrids in a population from British Columbia. Although the fitness and demographic consequences of hybridization during introduction require further investigation, the lower incidence of hybrids in western North America compared to Australia suggests that hybridization could have facilitated the establishment and rapid spread of C. maritima to a greater degree in Australia. In support of this hypothesis, the complete replacement of $C$. edentula by $C$. maritima phenotypes has not progressed as far north in western North America compared to Australia, where few northern populations of $C$. edentula remain. Indeed, although the introduction of $C$. maritima in western North America is more recent than Australia, migration rates for this species based on herbarium records are much lower in western North America (Barbour \& Rodman, 1970; Rodman, 1986). However, the mechanism and requires further investigation.

\subsection{Hybrid identification and significance}

497 The pattern of invasion first by C. edentula, then by C. maritima, has been repeated in three regions. 498 Prior to this study, hybrids were known only from Australia. However, we also identified clear evidence of hybridization in western North America and in New Zealand. Hybrids between the two 
1974) and our data demonstrate that recent and advanced generation hybrids are at least partially

502 fertile in natural populations. Our results show backcrossing to both parental species, although

503 backcrossing to C. maritima was much more frequent. This pattern of biased backcrossing towards

504 C. maritima was predicted based on field observations of pollinator visitations (Mesgaran et al.,

505 2016), the morphological replacement of $C$. edentula by C. maritima, and previous genetic studies

506 (Mesgaran et al., 2016; Ohadi et al., 2016). It is also consistent with expected mating asymmetries between these species and their hybrids caused by the inheritance of the self-incompatibility system and traits associated with pollinator attraction in hybrids (Li et al., 2019). In artificial crosses, early generation hybrids inherited mostly (but not exclusively) self-incompatibility, as well as larger floral displays, similar to C. maritima ( $\mathrm{Li}$ et al., 2019). This suggests that F1 hybrids will often need to rely on outcrossing, and that larger floral displays should facilitate this. Consequently, these traits in the hybrids should further contribute to backcrossing to the self-incompatible parent (C. maritima). A similar asymmetric pattern of species ancestry has been identified in hybrids of other species with 514 such differences in mating system (Brandvain, Kenney, Flagel, Coop, \& Sweigart, 2014; Pickup et 515 al., 2019; Ruhsam, Hollingsworth, \& Ennos, 2011).

516 Our identification of advanced generation backcrosses to C. maritima means that portions of the $C$.

517 edentula genome have been retained in a largely C. maritima background (i.e. introgression), long 518 after morphological evidence of hybridization has gone from a population. The role of selection and 519 neutral evolutionary processes in governing patterns of introgression across the genome, however, 520 remains to be investigated in this system. Theory suggests that regions of the genome that are not 521 introgressed will harbour incompatibilities or a high number of additive deleterious alleles in the 522 introgressing species (Harris \& Nielsen, 2016; Juric, Aeschbacher, \& Coop 2016). A greater fixation 523 rate of weakly deleterious alleles is predicted in the C. edentula due to its higher level of inbreeding, 524 and indeed, the low levels of genetic variability in this species relative to C. maritima support a lower 525 effective population size in this species. Selection against a higher genetic load originating from $C$. 526 edentula in hybrids should more rapidly lead to the reconstitution of a C. maritima genome following 527 transient hybridization during range expansion. In line with the expectation of selection against 528 selfing ancestry in outcrossers, in Mimulus gutattus (outcrossing) genomic regions with high 529 recombination rates have reduced levels of ancestry from the selfing species Mimulus nasutus 530 (Brandvain et al., 2014). However, several remarkable examples in plants have demonstrated the 531 infusion of favorable alleles via hybridization (adaptive introgression), including the transfer of 532 herbivore resistance in Helianthus (Whitney, Randell, \& Rieseberg, 2006). Indeed, Cody and Cody 
533 (2004) proposed the intriguing possibility of adaptive introgression in the Cakile system but this

534 remains to be investigated. Our identification of replicated patterns of hybridization, replacement and

535 invasion in Cakile provide an exciting opportunity for further investigation of the beneficial and 536 detrimental consequences of hybridization during range expansion.

\section{Conclusion}

538 Here we confirm that, particularly in Australia, the apparent replacement of $C$. edentula by $C$. 539 maritima is not complete and remnants of the C. edentula genome are evident in contemporary $C$. 540 maritima populations. Furthermore, it appears that both early and later generation hybrids are at least 541 partially fertile in natural populations and that there is a higher frequency of backcrossing to $C$. 542 maritima. The patterns of hybridization we identified is consistent with the hypothesis that mating 543 among these cross-compatible invaders has facilitated the establishment of the self-incompatible $C$. 544 maritima whose range expansion may otherwise be limited due to Allee effects, as has been observed 545 in other potential self-incompatible invaders (Uesugi, Baker, de Silva, Nurkowski, \& Hodgins, 2020).

546 The evolutionary consequence of hybridization for both species remains unclear, as is its role, if any, 547 in the rapid expansion of one invader at the expense of another.

$548 \quad 6 \quad$ Author Contributions

$549 \mathrm{KH}, \mathrm{RC}$ and LR conceived of and designed the study. KH, KN and RC carried out sampling. KN 550 conducted the molecular laboratory work. HR carried out the bioinformatics analyses with significant 551 input from $\mathrm{AG}, \mathrm{PB}$ and $\mathrm{KH}$. AG, $\mathrm{KH}, \mathrm{LR}, \mathrm{PB}, \mathrm{RC}$ and $\mathrm{HR}$ contributed to the writing and approved 552 the final manuscript.

\section{$553 \quad 7 \quad$ Funding}

$554 \mathrm{KH}, \mathrm{RC}$ and LR received funding from the Australian Research Council (Grant ID: DP180102531). 555 HR was supported by Monash Graduate Scholarship (MGS).

$556 \quad 8 \quad$ Acknowledgments

557 We would like to thank all collectors of this study, Sarah Bou-assi for help with molecular laboratory 558 work and Lotte van Boheemen for help with the initial bioinformatics analysis.

5599 Data Availability Statement

This article is protected by copyright. All rights reserved 
560 Sequence data are available at the National Center for Biotechnology Information Sequence Read

561 Archive under Bioproject PRJNA637114. Unfiltered dataset available on

562 https://bridges.monash.edu/articles/dataset/GBSCAK_vcf_gz/12526220/1; filtered dataset on

563 https://bridges.monash.edu/articles/dataset/filtered_dataset_GBS_Cakile/12996854. Scripts are

564 available on https://github.com/HannaRos/Cakile-GBS-scripts.

\section{Data reference}

566 [dataset]. Rosinger, H.S., Geraldes, A. M., Nurkowski, K. A., Battlay, P., Cousens, R. D., Rieseberg,

567 L. H., Hodgins, K. A.; 2020; GBSCAK.vef.gz; Monash University Bridges;

568 https://doi.org/10.26180/5ef01e7a6359b

569 [dataset]. Rosinger, H.S., Geraldes, A. M., Nurkowski, K. A., Battlay, P., Cousens, R. D., Rieseberg,

570 L. H., Hodgins, K. A.; 2020; filtered dataset GBS Cakile; Monash University Bridges;

571 https://doi.org/10.26180/5f6be2a84dc4d

\section{$572 \quad 11 \quad$ References}

573 Abbott, R. J. (1992). Plant invasions, interspecific hybridization and the evolution of new plant taxa.

574 Trends in Ecology \& Evolution, 7(12), 401-405.

575 Alexander, D. H., Novembre, J., \& Lange, K. (2009). Fast model-based estimation of ancestry in 576 unrelated individuals. Genome Research, 19(9), 1655-1664. https://doi.org/10.1101/gr.094052.109

577 Anderson, E. C., \& Thompson, E. A. (2002). A model-based method for identifying species hybrids

578 using multilocus genetic data. Genetics, 160(3), 1217-1229.

579 Baack, E., Melo, M. C., Rieseberg, L. H., \& Ortiz-Barrientos, D. (2015). The origins of reproductive

580 isolation in plants. New Phytologist, 207(4), 968-984. https://doi.org/10.1111/nph.13424

581 Baker, H. G. (1965) Characteristics and modes of origin of weeds. In: The Genetics of Colonizing

582 Species (eds Baker H, Stebbins G), pp. 147-168. Academic Press, New York.

583 Baker, H. G. (1974). The evolution of weeds. Annual Review of Ecology and Systematics, 5(1), 1-24.

584 https://doi.org/10.1146/annurev.es.05.110174.000245

585 Ball, P. W. (1964). A revision of Cakile in Europe. Feddes Repertorium, 69, 35-40.

586 Barbour, M. G. (1970). Seedling ecology of Cakile maritima along the California coast. Bulletin of

587 the Torrey Botanical Club, 280-289. https://doi.org/10.2307/2483647

588 Barbour, M. G., \& Rodman, J. E. (1970). Saga of the West Coast sea-rockets: Cakile edentula ssp.

589 californica and C. maritima. Rhodora, 72(791), 370-386.

This article is protected by copyright. All rights reserved 
Bock, C.H. (2008) The effect of Alternaria brassicicola infection on the reproductive fitness of the naturally occurring littoral ruderals Cakile maritima and C. edentula. Australian Plant Pathology 37(6), 569-580. https://doi.org/10.1071/AP08057

593 Bock, D. G., Caseys, C., Cousens, R. D., Hahn, M. A., Heredia, S. M., Hübner, S., ... Rieseberg, L. H. (2015). What we still don't know about invasion genetics. Molecular Ecology, 24(9), 2277-2297. https://doi.org/10.1111/mec.13032

Brandvain, Y., Kenney, A. M., Flagel, L., Coop, G., \& Sweigart, A. L. (2014). Speciation and Introgression between Mimulus nasutus and Mimulus guttatus. PLoS Genet 10(6) : e1004410. https://doi:10.1371/journal.pgen.1004410

Catchen, J. M., Amores, A., Hohenlohe, P., Cresko, W., \& Postlethwait, J. H. (2011). Stacks:

600 building and genotyping loci de novo from short-read sequences. G3: Genes, Genomes, Genetics, 1(3), 171-182. https://doi.org/10.1534/g3.111.000240

Boyd, R. S., \& Barbour, M. G. (1993). Replacement of Cakile edentula by C. maritima in the strand habitat of California. American Midland Naturalist, 209-228. https://doi.org/10.2307/2426122

604 Clausing, G., Vickers, K., \& Kadereit, J. W. (2000). Historical biogeography in a linear system: genetic variation of Sea Rocket (Cakile maritima) and Sea Holly (Eryngium maritimum) along European coasts. Molecular Ecology, 9(11), 1823-1833. https://doi.org/10.1046/j.1365294x.2000.01083.x

608 Cody, T. W., \& Cody, M. L. (2004). Morphology and spatial distribution of alien sea-rockets (Cakile spp.) on South Australian and Western Canadian beaches. Australian Journal of Botany, 52(2), 175610183.

611 Cousens, R. D., Ades, P. K., Mesgaran, M. B., \& Ohadi, S. (2013). Reassessment of the invasion 612 history of two species of Cakile (Brassicaceae) in Australia. Cunninghamia, 13, 275-290.

613 Cousens, R. D., \& Cousens, J. M. (2011). Invasion of the New Zealand coastline by European sea614 rocket (Cakile maritima) and American sea-rocket (Cakile edentula). Invasive Plant Science and 615 Management, 4(2), 260-263.

616 Danecek, P., Auton, A., Abecasis, G., Albers, C. A., Banks, E., DePristo, M. A., ... McVean, G. 617 (2011). The variant call format and VCFtools. Bioinformatics, 27(15), 2156-2158.

618 https://doi.org/10.1093/bioinformatics/btr330

619 Dlugosch, K. M., \& Parker, I. M. (2008). Founding events in species invasions: genetic variation, 620 adaptive evolution, and the role of multiple introductions. Molecular Ecology, 17(1), 431449. doi:10.1111/j.1365-294X.2007.03538.x 
622 Ellstrand, N. C., \& Schierenbeck, K. A. (2000). Hybridization as a stimulus for the evolution of

623 invasiveness in plants?. Proceedings of the National Academy of Sciences, 97(13), 7043-7050.

624 https://doi.org/10.1073/pnas.97.13.7043

625 Fitzpatrick, B. M. (2012). Estimating ancestry and heterozygosity of hybrids using molecular

626 markers. BMC Evolutionary Biology, 12(1), 131. https://doi.org/10.1186/1471-2148-12-131

627 Fox, J. \& Weisberg S. (2019). An R companion to applied regression, third Edition. Thousand Oaks

628 CA: Sage. URL: https://socialsciences.mcmaster.ca/jfox/Books/Companion/

629 Francis, R. M. (2017). pophelper: an R package and web app to analyse and visualize population

630 structure. Molecular Ecology Resources, 17(1), 27-32. https://doi.org/10.1111/1755-0998.12509

631 Gandour, M., Hessini, K., \& Abdelly, C. (2008). Understanding the population genetic structure of

632 coastal species (Cakile maritima): seed dispersal and the role of sea currents in determining

633 population structure. Genetics Research, 90(2), 167-178.

634 https://doi.org/10.1017/S0016672308009269

635 Gormally, C. L., Hamrick, J.L., \& Donovan, J. H. A. (2011). Genetic structure of a widely dispersed

636 beach annual, Cakile edentula (Brassicaceae). American Journal of Botany, 98(10), 1657-1662.

637 https://doi.org/10.3732/ajb.1000499

638 Harris, K., \& Nielsen, R. (2016). The genetic cost of Neanderthal introgression. Genetics, 203(2),

639 881-891. https://doi.org/10.1534/genetics.116.186890

640 Harrison, B. J., \& Darby, L. A. (1955). Unilateral hybridization. Nature, 176(4490), 982-982.

641 https://doi.org/10.1038/176982a0

642 Heyligers, P.C. (1984). Beach invaders: sea rockets and beach daisies thrive. Australian Natural

643 History; 21(5),212-214

644 Hodgins, K. A., Bock, D. G., \& Rieseberg, L. H. (2018). Trait evolution in invasive species. Annual

645 Plant Reviews Online, 459-496. https://doi.org/10.1002/9781119312994.apr0643

646 Hoffmann, B. D., \& Broadhurst, L. M. (2016). The economic cost of managing invasive species in

647 Australia. NeoBiota, 31, 1. https://doi.org/10.3897/neobiota.31.6960

648 Hovick, S. M., \& Whitney, K. D. (2014). Hybridisation is associated with increased fecundity and

649 size in invasive taxa: meta-analytic support for the hybridisation-invasion hypothesis. Ecology

650 Letters, 17(11), 1464-1477. https://doi.org/10.1111/ele.12355

651 Huebner, D. C. (2009). A morphological, molecular and experimental assessment of the conservation

652 status of great lakes sea-rocket (Cakile edentula var. lacustris, Brassicaceae) (Unpublished doctoral

653 dissertation). Northwestern University.

This article is protected by copyright. All rights reserved 
654 Huson, D. H., \& Bryant, D. (2006). Application of phylogenetic networks in evolutionary studies.

655 Molecular Biology and Evolution, 23(2), 254-267. https://doi.org/10.1093/molbev/msj030

656 Joshi, N. A. and Fass, J. N. (2011). Sickle: a Sliding-Window, Adaptive, Quality-Based Trimming

657 Tool for FastQ Files (Version 1.33) [Software]. Retrieved from https://github.com/najoshi/sickle

658 Juric, I., Aeschbacher, S., \& Coop, G. (2016). The strength of selection against Neanderthal

659 introgression. PLoS Genetics, 12(11), e1006340. https://doi.org/10.1371/journal.pgen.1006340

660 Kadereit, J. W., Arafeh, R., Somogyi, G., \& Westberg, E. (2005). Terrestrial growth and marine

661 dispersal? Comparative phylogeography of five coastal plant species at a European scale. Taxon,

662 54(4), 861-876. https://doi.org/10.2307/25065567

663 Kassambara, A. (2020). Ggpubr: ggplot2 Based Publication Ready Plots. R package version 0.2.5 [R

664 package]. A Retrieved from https://cran.r-project.org/package=ggpubr

665 Keenan, K., McGinnity, P., Cross, T. F., Crozier, W. W., \& Prodöhl, P. A. (2013). DiveRsity: An R 666 package for the estimation of population genetics parameters and their associated errors. Methods

667 Ecoly Evolution, 4(8), 782-788. doi:10.1111/2041-210X.12067

668 Lapointe, M.(2000). Modern diatom assemblages in surface sediments from the Maritime Estuary

669 and the Gulf of St. Lawrence, Québec (Canada). Marine Micropaleontology, 40(1-2), 43-65.

670 https://doi.org/0.1016/S0377-8398(00)00031-1

671 Li, C., Cousens, R. D., \& Mesgaran, M. B. (2019). How can natural hybridisation between

672 self-compatible and self-incompatible species be bidirectional?. Weed Research, 59(5), 339-348.

673 https://doi.org/10.1111/wre.12372

674 Li, H. \& Durbin, R. (2009). Fast and accurate short read alignment with Burrows- Wheeler

675 transform. Bioinformatics 25, 1754-1760. https://doi.org/10.1093/bioinformatics/btp324

676 Li, C., Mesgaran, M. B., Ades, P. K., \& Cousens, R. D. (2020). Inheritance of breeding system in

677 Cakile (Brassicaceae) following hybridization: implications for plant invasions. Annals of Botany,

678 125(4), 639-650. https://doi.org/10.1093/aob/mcz198

679 Maddison, W. P. and Maddison, D.R. (2019). Mesquite: A Modular System for Evolutionary

680 Analysis [Software]. Retrieved from http://www.mesquiteproject.org

681 Marhold, K.(2011). Brassicaceae. In: Euro+Med Plantbase- the Information Resource for Euro-

682 Mediterranean Plant Diversity. Retrieved from

683 http://ww2.bgbm.org/EuroPlusMed/PTaxonDetail.asp?NameId=14225\&PTRefFk=7200000

684 Mesgaran, M. B., Lewis, M. A., Ades, P. K., Donohue, K., Ohadi, S., Li, C., \& Cousens, R. D.

685 (2016). Hybridization can facilitate species invasions, even without enhancing local adaptation.

This article is protected by copyright. All rights reserved 
Proceedings of the National Academy of Sciences, 113(36), 10210-10214.

687 https://doi.org/10.1073/pnas.1605626113

688 Ohadi, S., Ades, P. K., Ford, R., Strand, A. E., Tibbits, J., Mesgaran, M. B., \& Cousens, R. D.

689 (2016). Genetic structure along the strandline: Unravelling invasion history in a one-dimensional

690 system. Journal of Biogeography, 43(3), 451-460. https://doi.org/10.1111/jbi.12640

691 Payseur, B. A., \& Rieseberg, L. H. (2016). A genomic perspective on hybridization and speciation.

692 Molecular Ecology, 25(11), 2337-2360. https://doi.org/10.1111/mec.13557

693 Pickrell, J.K., \& Pritchard, J.K. (2012). Inference of population splits and mixtures from genome-

694 wide allele frequency data. PLoS Genetics, In Press.

695 Pickup, M., Brandvain, Y., Fraïsse, C., Yakimowski, S., Barton, N. H., Dixit, T., ... Field, D. L.

696 (2019). Mating system variation in hybrid zones: facilitation, barriers and asymmetries to gene flow.

697 New Phytologist, 224(3), 1035-1047. https://doi.org/10.1111/nph.16180

698 Pimentel, D., Zuniga, R., \& Morrison, D. (2005). Update on the environmental and economic costs

699 associated with alien-invasive species in the United States. Ecological Economics, 52(3), 273-288.

700 https://doi.org/10.1016/j.ecolecon.2004.10.002

701 Pollak, E. (1987). On the theory of partially inbreeding finite populations. I. Partial selfing. Genetics,

$702117(2), 353-360$.

703 Poplin, R., Ruano-Rubio, V., DePristo, M. A., Fennell, T. J., Carneiro, M. O., Van der Auwera, G.

704 A., ... Shakir, K. (2017). Scaling accurate genetic variant discovery to tens of thousands of samples.

705 BioRxiv, 201178. https://doi.org/10.1101/201178

706 Reich, D., Thangaraj, K., Patterson, N., Price, A. L., \& Singh, L. (2009). Reconstructing Indian

707 population history. Nature, 461(7263), 489-494. https://doi.org/10.1038/nature08365

708 Rodman, J. E. (1974). Systematics and evolution of the genus Cakile (Cruciferae). Contributions

709 from the Gray Herbarium of Harvard University, (205), 3-146.

710 Rodman, J. E. (1976). Differentiation and migration of Cakile (Cruciferae): seed glucosinolate

711 evidence. Systematic Botany, 137-148.

712 Rodman, J. E. (1986). Introduction, establishment and replacement of sea-rockets (Cakile,

713 Cruciferae) in Australia. Journal of Biogeography, 159-171. https://doi.org/10.2307/2844990

714 R Core Team (2018). R: A language and environment for statistical computing. R Foundation for

715 Statistical Computing, Vienna, Austria. URL https:/www.R-project.org/.

716 Ruiz, G. M., Rawlings, T. K., Dobbs, F. C., Drake, L. A., Mullady, T., Huq, A., \& Colwell, R. R.

717 (2000). Global spread of microorganisms by ships. Nature, 408(6808), 49-50.

718 https://doi.org/10.1038/35040695

This article is protected by copyright. All rights reserved 
719 Ruhsam, M., Hollingsworth, P. M., \& Ennos, R. A. (2011). Early evolution in a hybrid swarm

720 between outcrossing and selfing lineages in Geum. Heredity, 107(3), 246-255.

721 https://doi.org/10.1038/hdy.2011.9

722 Sakai, A. K., Allendorf, F. W., Holt, J. S., Lodge, D. M., Molofsky, J., With, K. A., ... McCauley, D.

723 E. (2001). The population biology of invasive species. Annual review of Ecology and Systematics,

724 32(1), 305-332. https://doi.org/10.1146/annurev.ecolsys.32.081501.114037

725 Sax, D. F., \& Gaines, S. D. (2003). Species diversity: from global decreases to local increases.

726 Trends in Ecology \& Evolution, 18(11), 561-566.

727 Simberloff, D.(2013). Biological invasions: Prospects for slowing a major global change. Elementa

728 Science of the Anthropcene, 1, p.000008. doi: http://doi.org/10.12952/journal.elementa.000008

729 Sedlazeck, F. J., Rescheneder, P., \& von Haeseler, A. (2013). NextGenMap: fast and accurate read

730 mapping in highly polymorphic genomes. Bioinformatics, 29(21), 2790-2791.

731 https://doi.org/10.1093/bioinformatics/btt468

732 Thrall, P. H., Young, A. G., \& Burdon, J. J. (2000). An analysis of mating structure in populations of

733 the annual sea rocket, Cakile maritima (Brassicaceae). Australian Journal of Botany, 48(6), 731-738.

734 https://doi.org/10.1071/BT99060

735 Todesco, M., Pascual, M. A., Owens, G. L., Ostevik, K. L., Moyers, B. T., Hübner, S., ... Rieseberg,

736 L. H. (2016). Hybridization and extinction. Evolutionary Applications, 9(7), 892-908.

737 https://doi.org/10.1111/eva.12367

738 Uesugi, A., Baker, D. J., de Silva, N., Nurkowski, K., \& Hodgins, K. A. (2020). A lack of genetically

739 compatible mates constrains the spread of an invasive weed. New Phytologist, 226(6), 1864-1872.

740 https://doi.org/10.1111/nph.16496

741 Vallejo-Marín, M., Friedman, J., Twyford, A. D., Lepais, O., Ickert-Bond, S. M., Streisfeld, M. A., ...

742 \& Puzey, J. R. (2020). Population genomic and historical analysis reveals a global invasion by

743 bridgehead processes in Mimulus guttatus. bioRxiv. https://doi.org/10.1101/2020.06.26.173286

744 Vallejo-Marín, M., \& Hiscock, S. J. (2016). Hybridization and hybrid speciation under global

745 change. New Phytologist, 211(4), 1170-1187. https://doi.org/10.1111/nph.14004

746 van Boheemen, L. A., Lombaert, E., Nurkowski, K. A., Gauffre, B., Rieseberg, L. H., \& Hodgins, K.

747 A. (2017). Multiple introductions, admixture and bridgehead invasion characterize the introduction

748 history of Ambrosia artemisiifolia in Europe and Australia. Molecular Ecology, 26(20), 5421-5434.

749 https://doi.org/10.1111/mec.14293

This article is protected by copyright. All rights reserved 
750 Vilatersana, R., Sanz, M., Galian, A., \& Castells, E. (2016). The invasion of Senecio pterophorus

751 across continents: multiple, independent introductions, admixture and hybridization. Biological

752 invasions, 18(7), 2045-2065. https://doi.org/10.1007/s10530-016-1150-1

753 Ward, S. M., Gaskin, J. F., \& Wilson, L. M. (2008). Ecological genetics of plant invasion: what do

754 we know?. Invasive Plant Science and Management, 1(1), 98-109. https://doi.org/10.1614/IPSM-07-

$755 \quad 022.1$

756 Weir, B. S., \& Cockerham, C. C. (1984). Estimating F-statistics for the analysis of population

757 structure. Evolution, 38, 1358-1370. https://doi.org/10.2307/2408641

758 Westberg, E. D. (2005). European phylogeography of the coastal plants Cakile maritima Scop.

759 (Brassicaceae) and Eryngium maritimum L. (Apiaceae) (Unpublished doctoral dissertation). Johannes

760 Gutenberg-Universität.

761 Whitlock, R., Hipperson, H., Mannarelli, M., \& Burke, T. (2008). A high-throughput protocol for

762 extracting high-purity genomic DNA from plants and animals. Molecular Ecology Resources, 8(4),

763 736-741. https://doi.org/10.1111/j.1755-0998.2007.02074.x

764 Whitney, K. D., Randell, R. A., \& Rieseberg, L. H. (2006). Adaptive introgression of herbivore

765 resistance traits in the weedy sunflower Helianthus annuus. The American Naturalist, 167(6), 794-

766 807. https://doi.org/10.1086/504606

767 Wickham, H., Averick, M., Bryan, J., Chang, W., McGowan, L., François, R., ... Kuhn, M. (2019).

768 Welcome to the Tidyverse. Journal of Open Source Software, 4(43), 1686.

769 https://doi.org/10.21105/joss.01686

770 Zheng, X., Levine, D., Shen, J., Gogarten, S. M., Laurie, C., \& Weir, B. S. (2012). A high-

771 performance computing toolset for relatedness and principal component analysis of SNP data.

772 Bioinformatics, 28(24), 3326-3328. https://doi.org/10.1093/bioinformatics/bts606

773

$774 \quad$ Figures and figure captions

This article is protected by copyright. All rights reserved 


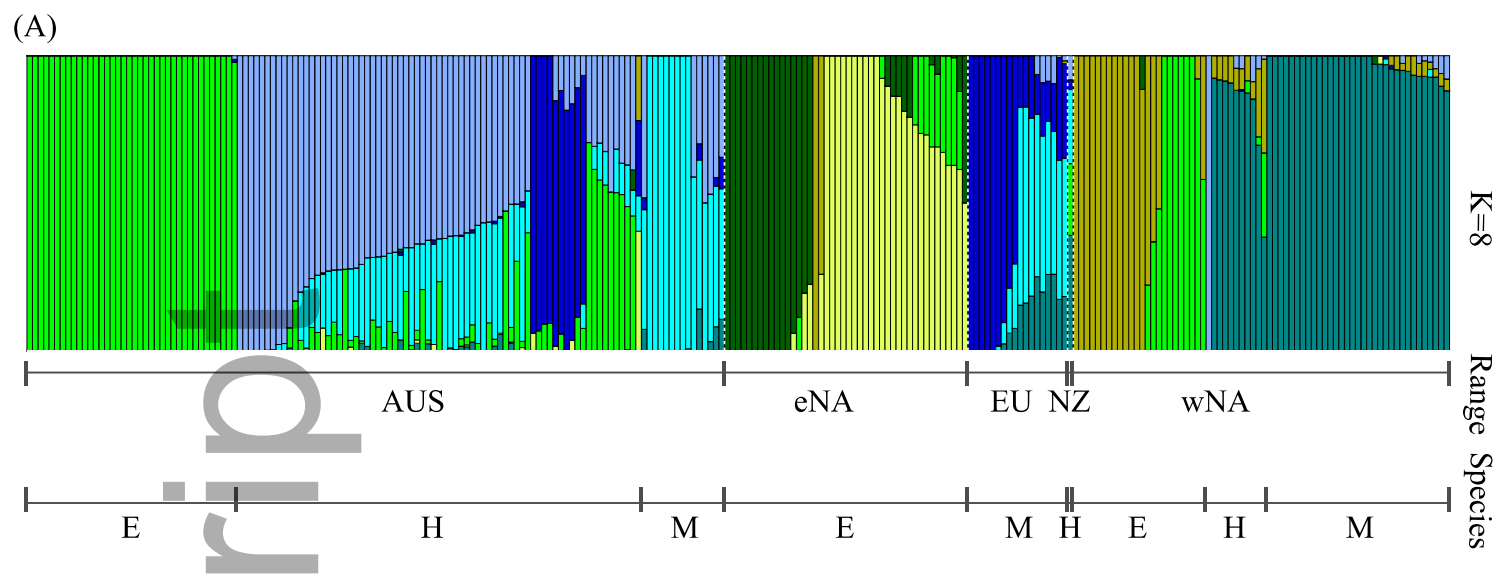

(B)


This article is protected by copyright. All rights reserved 
776 Figure 1 Admixture results of the unsupervised run of the global thinned dataset. (A) A distruct plot 777 for $\mathrm{K}=8$. Individuals are ordered according to their cluster association of the supervised run. 778 AUS=Australia, eNA= eastern North America, EU= Europe and northern Africa, NZ= New Zealand, 779 wNA=western North America. $\mathrm{E}=$ C. edentula, $\mathrm{M}=$ C. maritima, $\mathrm{H}=$ Hybrids. (B) Population pie 780 charts for $\mathrm{K}=8$, Admixture proportions for each population are displayed. A global map is displayed 781 as well as close ups of western North America, Europe, the Australian mainland and Tasmania. 782 Colours correspond to the clusters in the distruct plot. Arrows indicates direction of invasion and 783 direction of Spearman test.

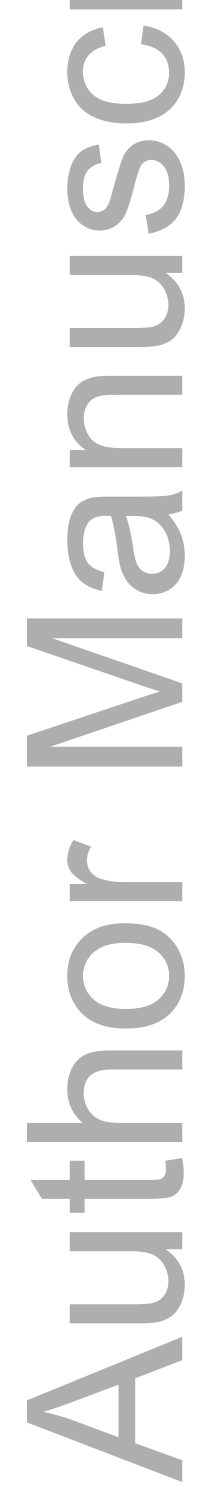




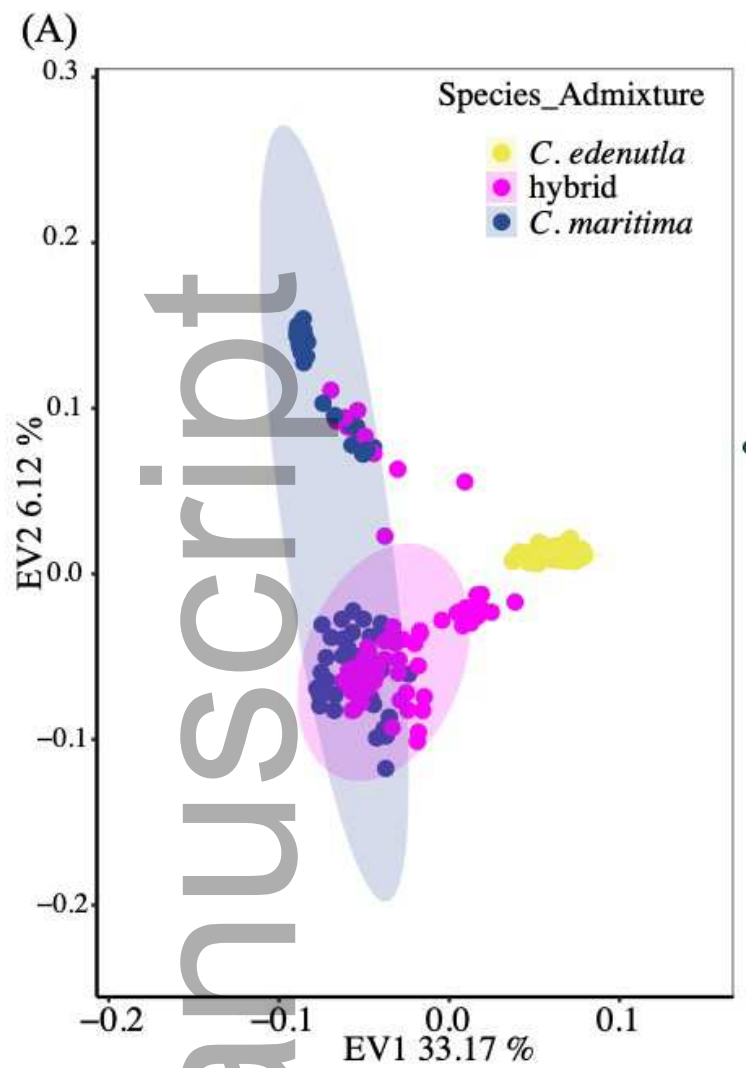

(B)

(C)

EV1 $33.17 \%$
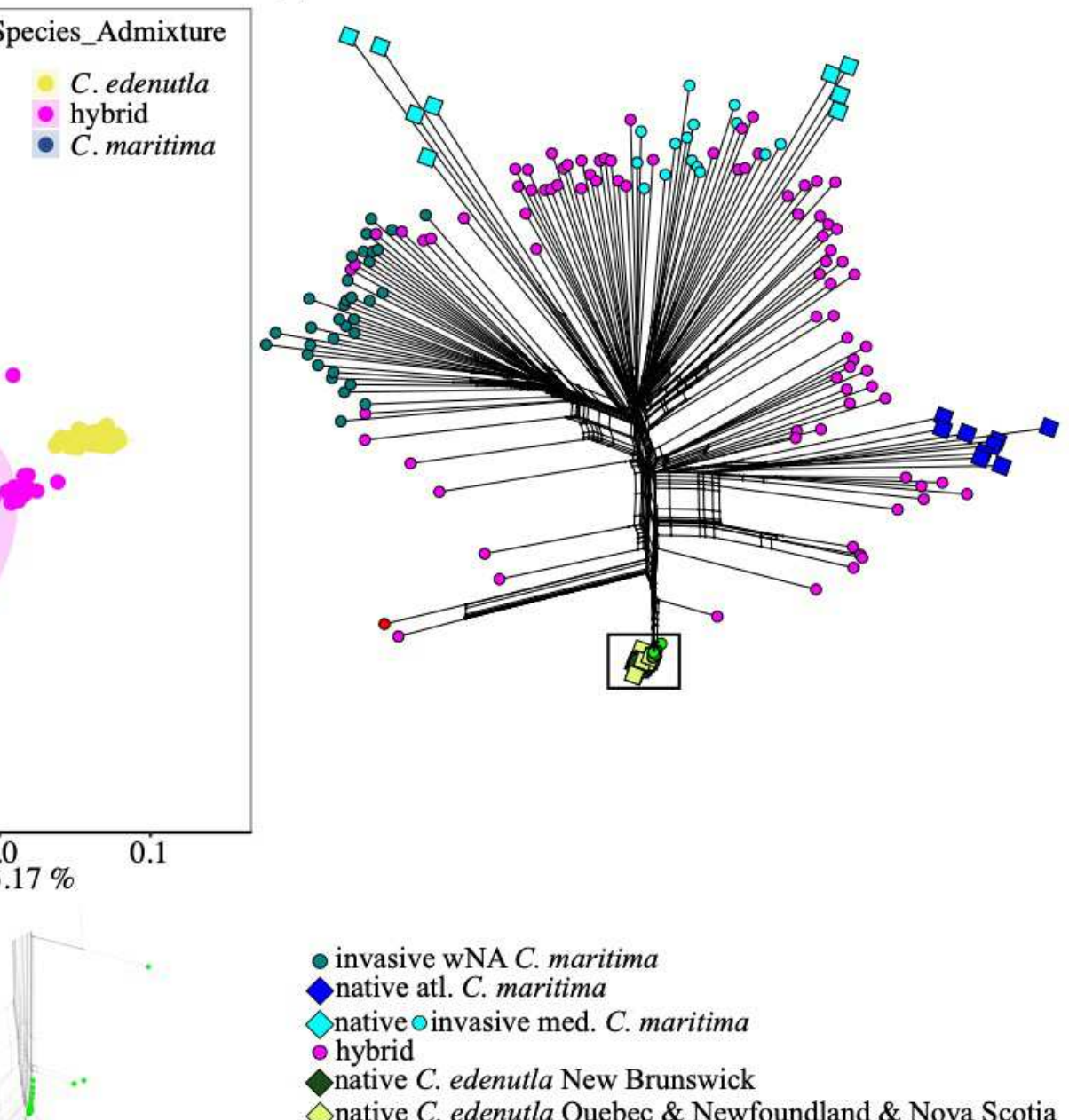

- invasive wNA C. maritima

native atl. C. maritima

native oinvasive med. C. maritima

hybrid

native C. edenutla New Brunswick

$\triangle$ native C. edenutla Quebec \& Newfoundland \& Nova Scotia o invasive C. edenutla Nova Scotia

$\checkmark$ native $\odot$ invasive $C$. edenutla Lake Michigan \& Rhode Island

785 Figure 2 (A) Principal component analysis of the global thinned dataset. First two eigenvectors are

786 presented. Individuals are coloured according to their species and hybrid status based on the

787 supervised run of Admixture. Ellipses indicate the $95 \%$ confidence range of the cluster. (B) Splitstree

788 network of the global Splitstree dataset. Individuals are coloured according to their predominant

789 cluster of the unsupervised run of Admixture cluster ( $\mathrm{K}=8$ of the global thinned dataset), with

790 hybrids identified using the supervised run. The shapes indicate native vs. invasive range. 


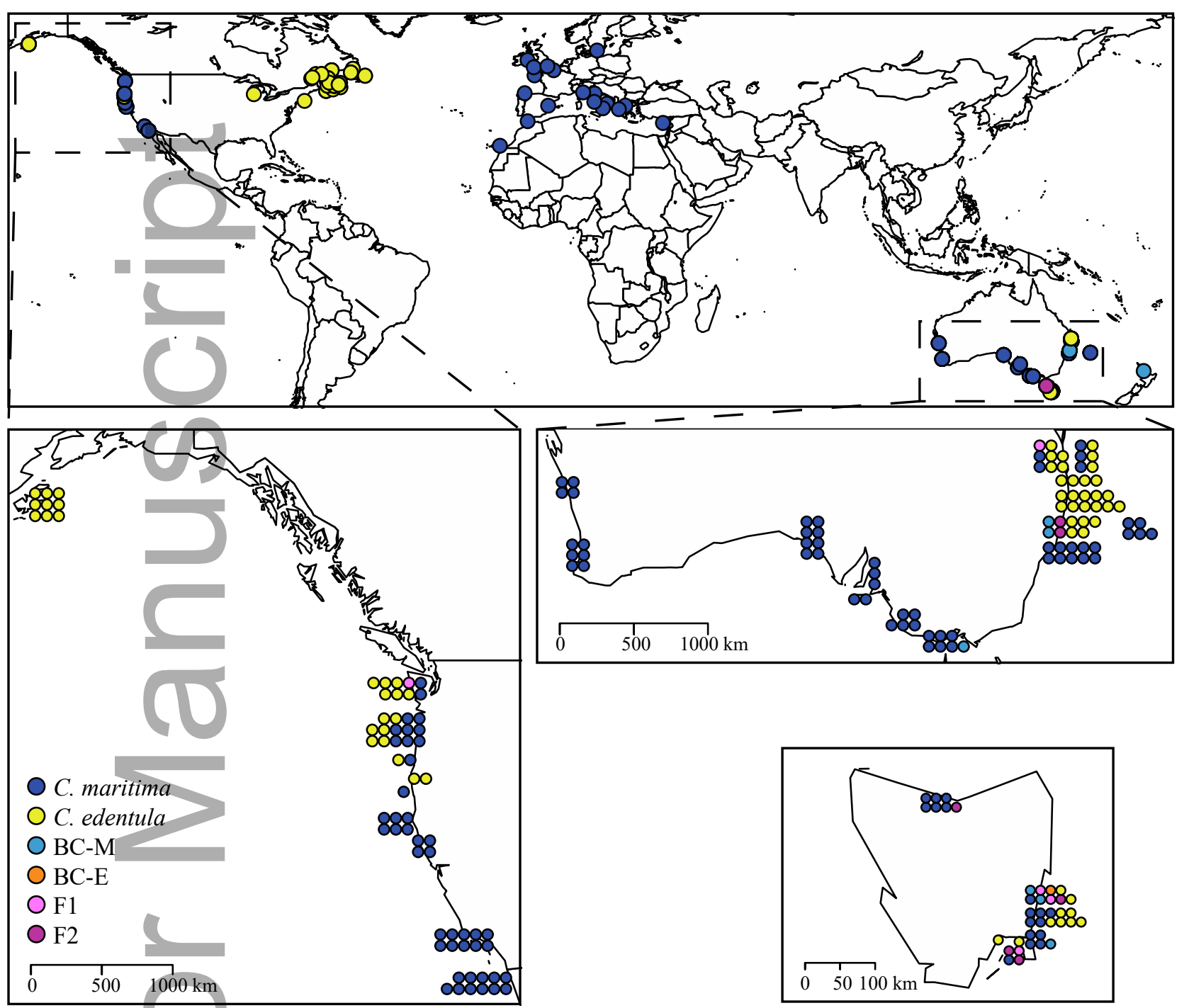

793 Figure 3 Geographic distribution of the hybrid assignment test by NewHybrid. Individuals are

794 coloured according to their NewHybrid classification. A global map and close-ups of western North

795 America, the Australian mainland and Tasmania are presented. $\mathrm{BC}-\mathrm{E}=$ backcross to C. edentula, $\mathrm{BC}$ -

$796 \mathrm{M}=$ backcross to C. maritima. 
(A)
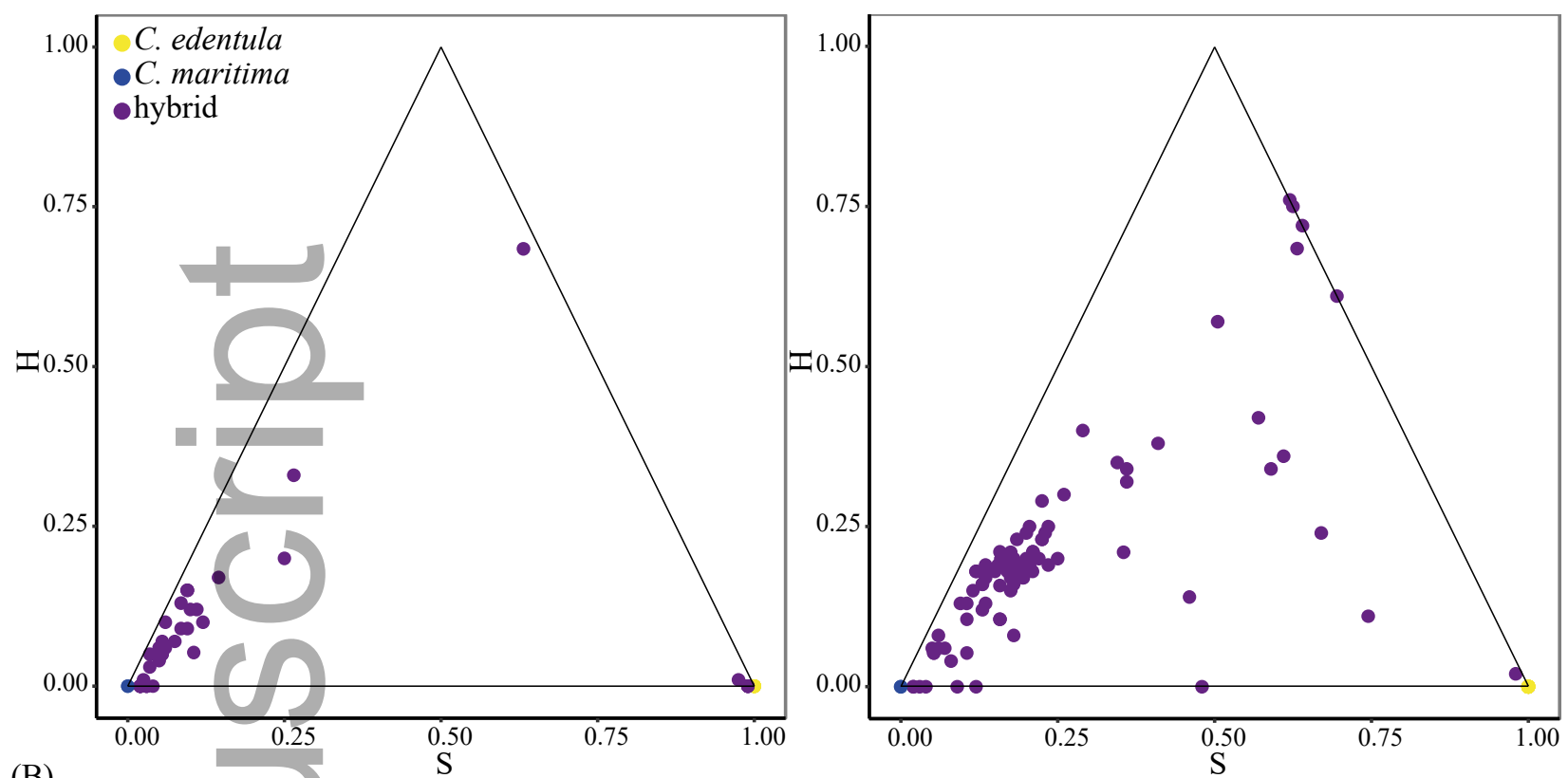

(B)
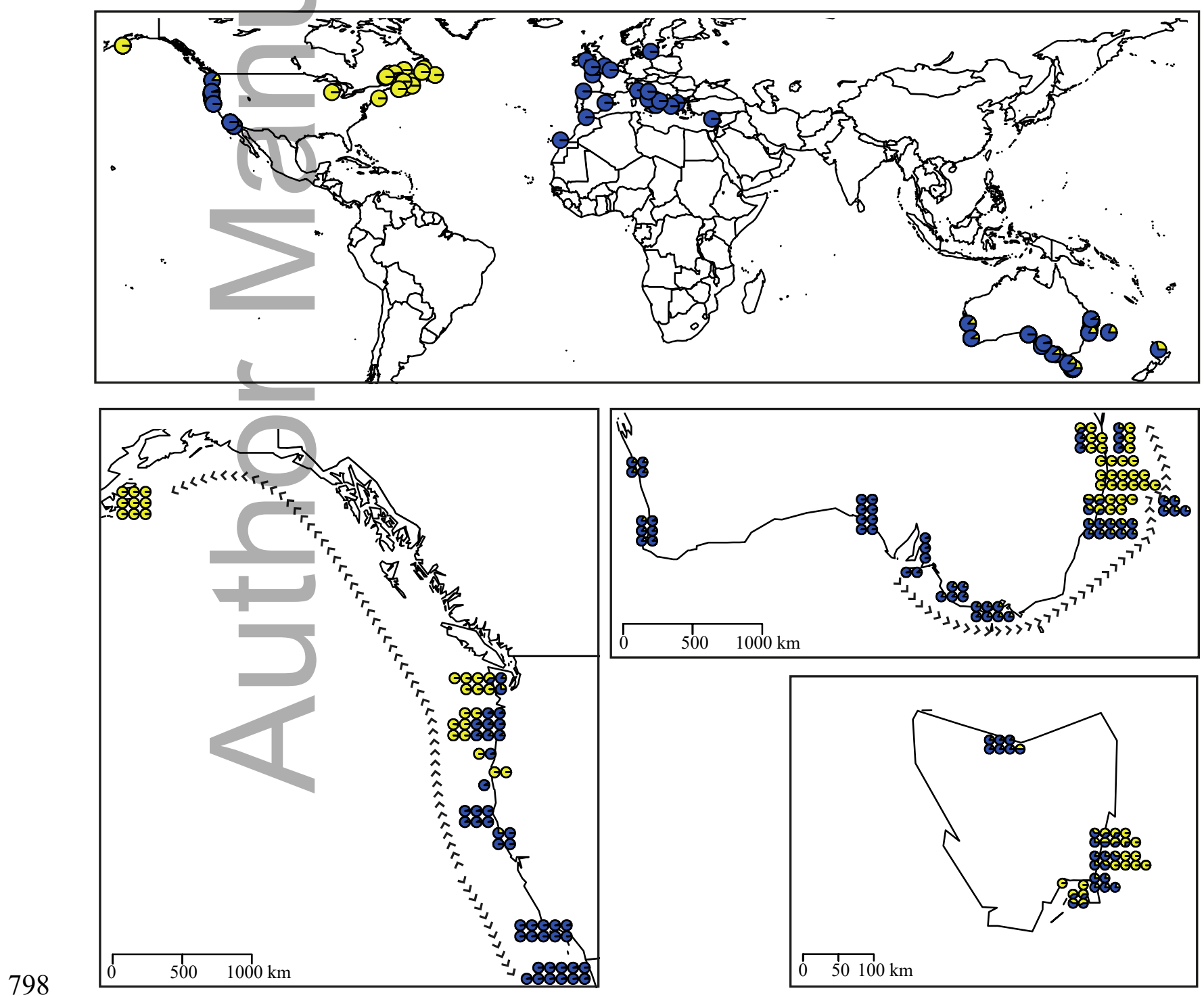

This article is protected by copyright. All rights reserved 
799 Figure 4 Results of a hybridization assignment test implemented by HIest using 471 SNPs (0.99, 800 0.03). (A) Association of ancestry index (S) and interclass heterozygosity $(\mathrm{H})$ are given for western 801 North America (left) and Australia (right). Individuals are coloured according to their HIest 802 classification. For hybrids the continuous model was a better fit than the hybrid classes. (B) The 803 geographic distribution of individuals and their $\mathrm{S}$ index; yellow $=C$. edentula proportion, blue $=C$. 804 maritima proportion. A global map and close-ups of western North America, the Australian mainland 805 and Tasmania are presented. Arrows indicates direction of invasion and direction of Spearman's test.

806

807

808
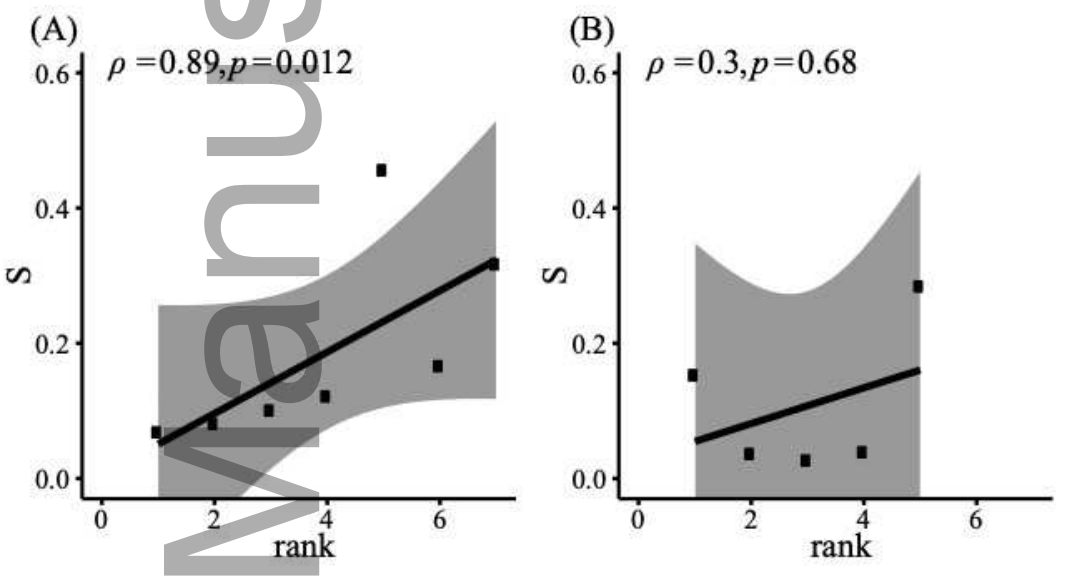

809 Figure 5 Results of the Spearman correlation test displayed (Table 2). The associations between 810 population mean Q values of hybrids identified using the supervised Admixture run and the ranked 811 order of populations from the first entry point of C. maritima (A) in eastern Australia and (B) western 812 North America.

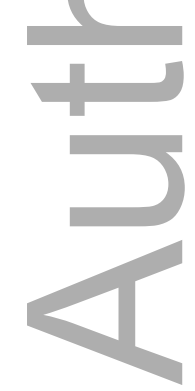


(A)

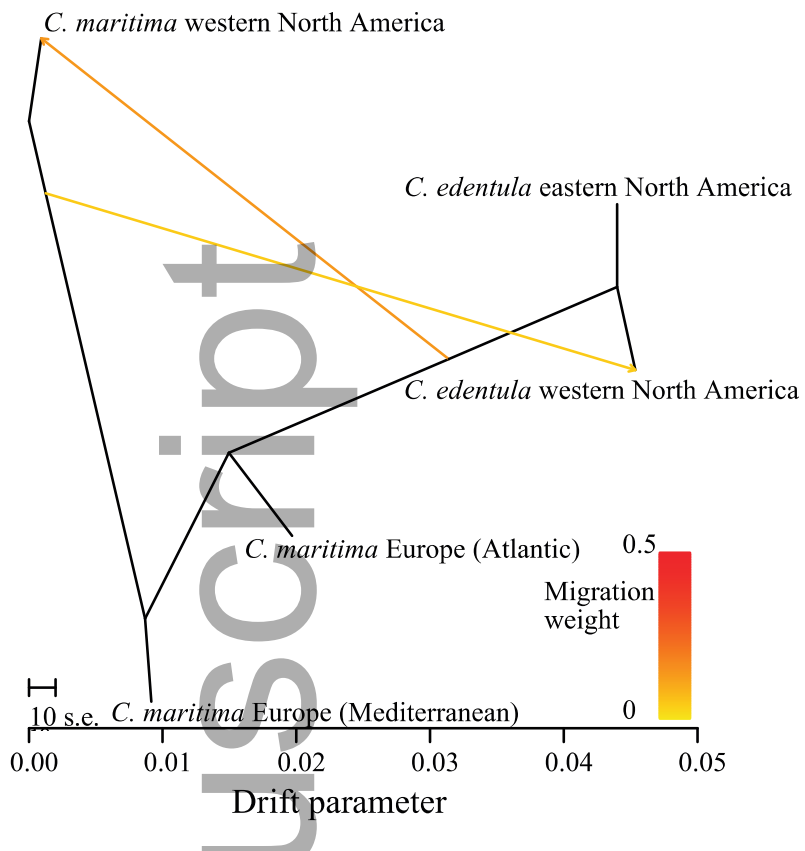

(B)

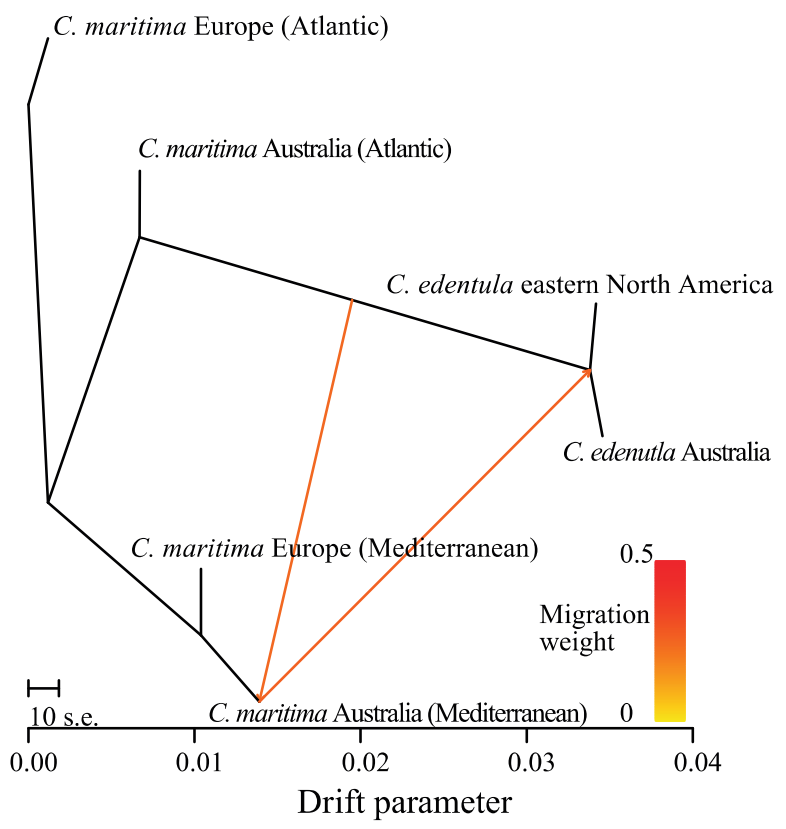

815

816 Figure 6 Maximum likelihood trees with two migration events generated by TreeMix. Native ranges 817 and (A) western North America, (B) Australia. Individuals are grouped by species (identified 818 morphologically), likely subspecies and geographic origin. 
819 Table 1 Number of individuals and sampling locations as well as mean number of individuals sampled per sampling location in each range is 820 presented.

821

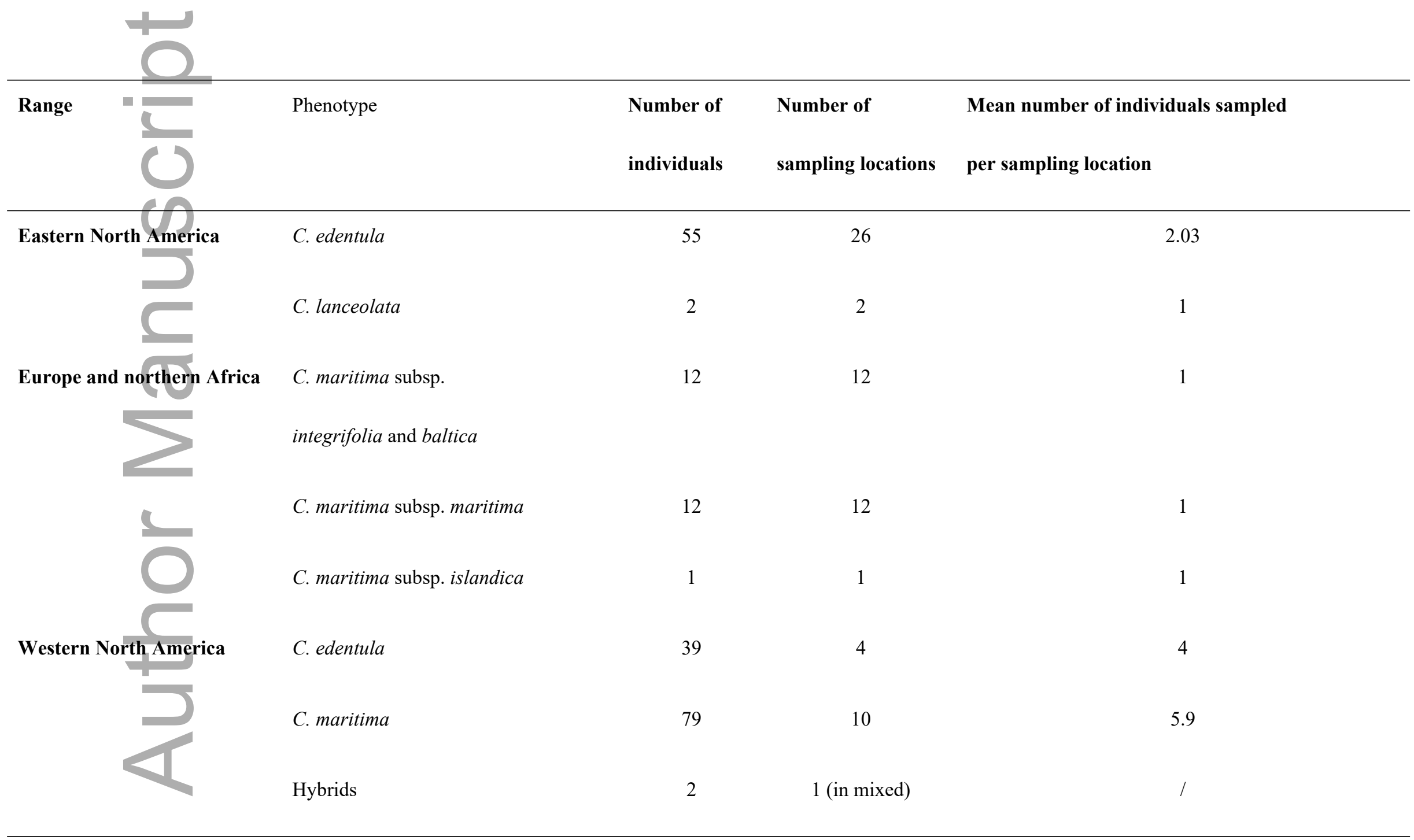

This article is protected by copyright. All rights reserved 


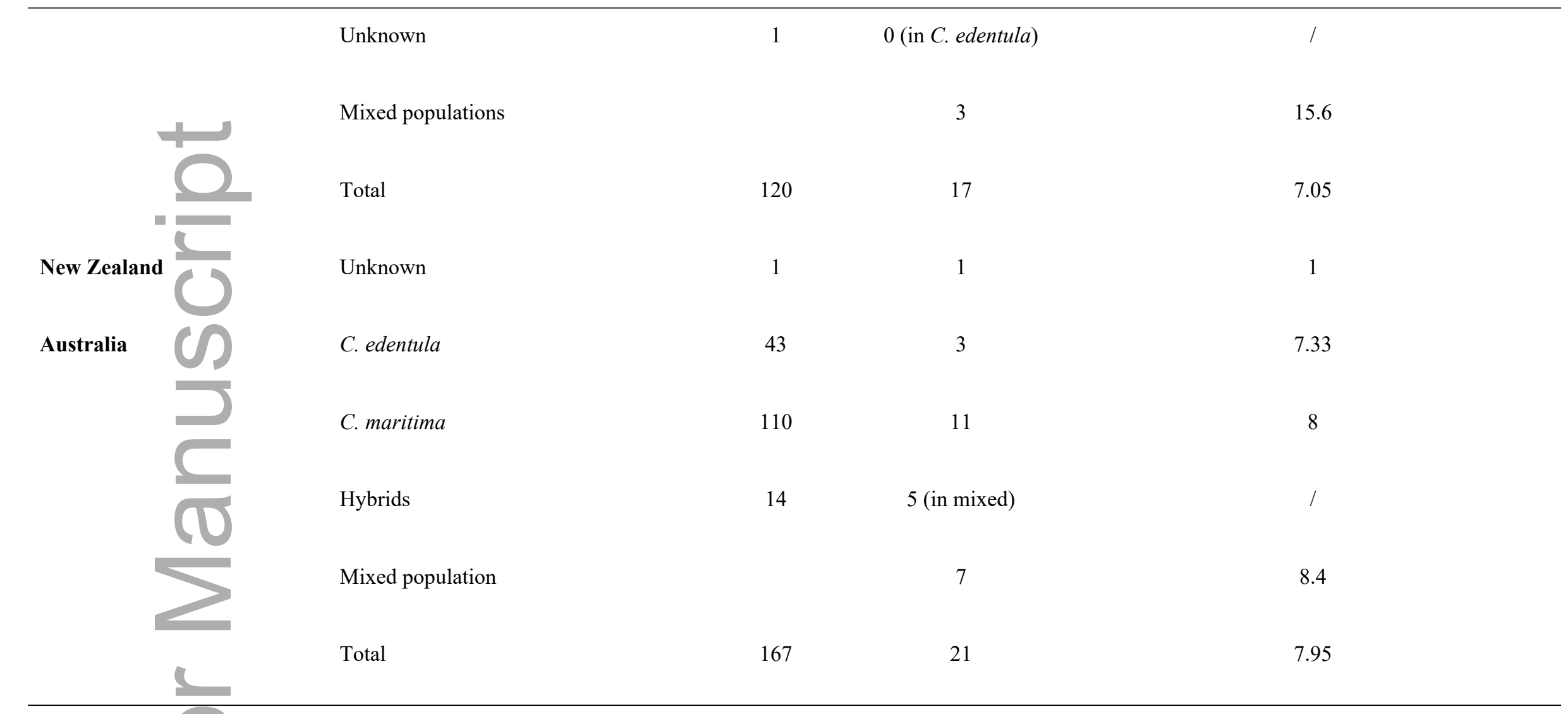

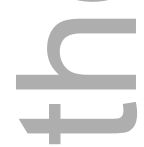

824 Table 2 Results of the Spearman's rank correlation test in the introduced ranges examining the association between species ancestry for $C$. 825 edentula, C. maritima and hybrids or hybrids and the rank order of sampling locations based on the distance along the coastline from the 826 first recorded case of C. maritima in western North America (San Francisco) or south-east mainland of Australia (Adelaide). Spearman's 827 Rank Correlation Coefficient $\rho$ and $\mathrm{p}$ values are presented for correlation between Q-value of the supervised run of the C. edentula cluster 
828 for each population in western North America and Australia and correlation between ancestry index (S) (Figure 4) and rank order of 829 sampling locations.

\begin{tabular}{|c|c|c|c|c|c|c|c|}
\hline$a$ & & & $\mathbf{Q}$ & & & $\mathbf{S}$ & \\
\hline Range & Species & $\begin{array}{l}\text { \# populations (\# } \\
\text { individuals) }\end{array}$ & $\rho$ & $\mathrm{p}$ & $\begin{array}{l}\text { \# populations } \\
\text { (\# individuals) }\end{array}$ & $\rho$ & $\mathrm{p}$ \\
\hline south-east Aus & $\begin{array}{l}\text { C. edentula, C. maritima, } \\
\text { hybrids }\end{array}$ & $10(65)$ & 0.815 & 0.004 & $10(65)$ & 0.815 & 0.004 \\
\hline & Hybrids & $7(30)$ & 0.893 & 0.012 & $8(38)$ & 0.905 & 0.005 \\
\hline $\begin{array}{l}\text { western North } \\
\text { America }\end{array}$ & $\begin{array}{l}\text { C. edentula, C. maritima, } \\
\text { hybrids }\end{array}$ & $10(68)$ & 0.511 & 0.132 & $10(68)$ & 0.576 & 0.088 \\
\hline all sampling locations & Hybrids & $5(11)$ & 0.300 & 0.683 & $10(50)$ & 0.467 & 0.213 \\
\hline $\begin{array}{l}\text { western North } \\
\text { America }\end{array}$ & $\begin{array}{l}\text { C. edentula, C. maritima, } \\
\text { hybrids }\end{array}$ & $8(47)$ & 0.719 & 0.045 & $8(47)$ & 0.810 & 0.022 \\
\hline north of San Francisco & Hybrids & $5(11)$ & 0.300 & 0.683 & $7(30)$ & 0.679 & 0.110 \\
\hline
\end{tabular}

Table 3 Results of the $f_{3}$ statistic using TreeMix. Tests of admixture in the invasive range of Australia and western North America were done separately and both were based on three groups (hybrids, C. edentula, C. maritima). Hybrid classification was done according to the 834 supervised run of Admixture. The $f_{3}$ statistic, the standard error of $f_{3}$ and the Z-score are reported.

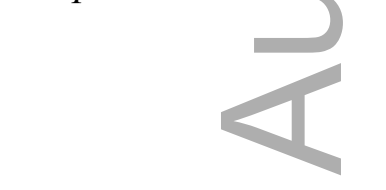

\begin{tabular}{|c|c|c|c|c|c|c|}
\hline Range & Target & Source 1 & Source 2 & $f_{3}$ & Standard error & Z-score \\
\hline
\end{tabular}




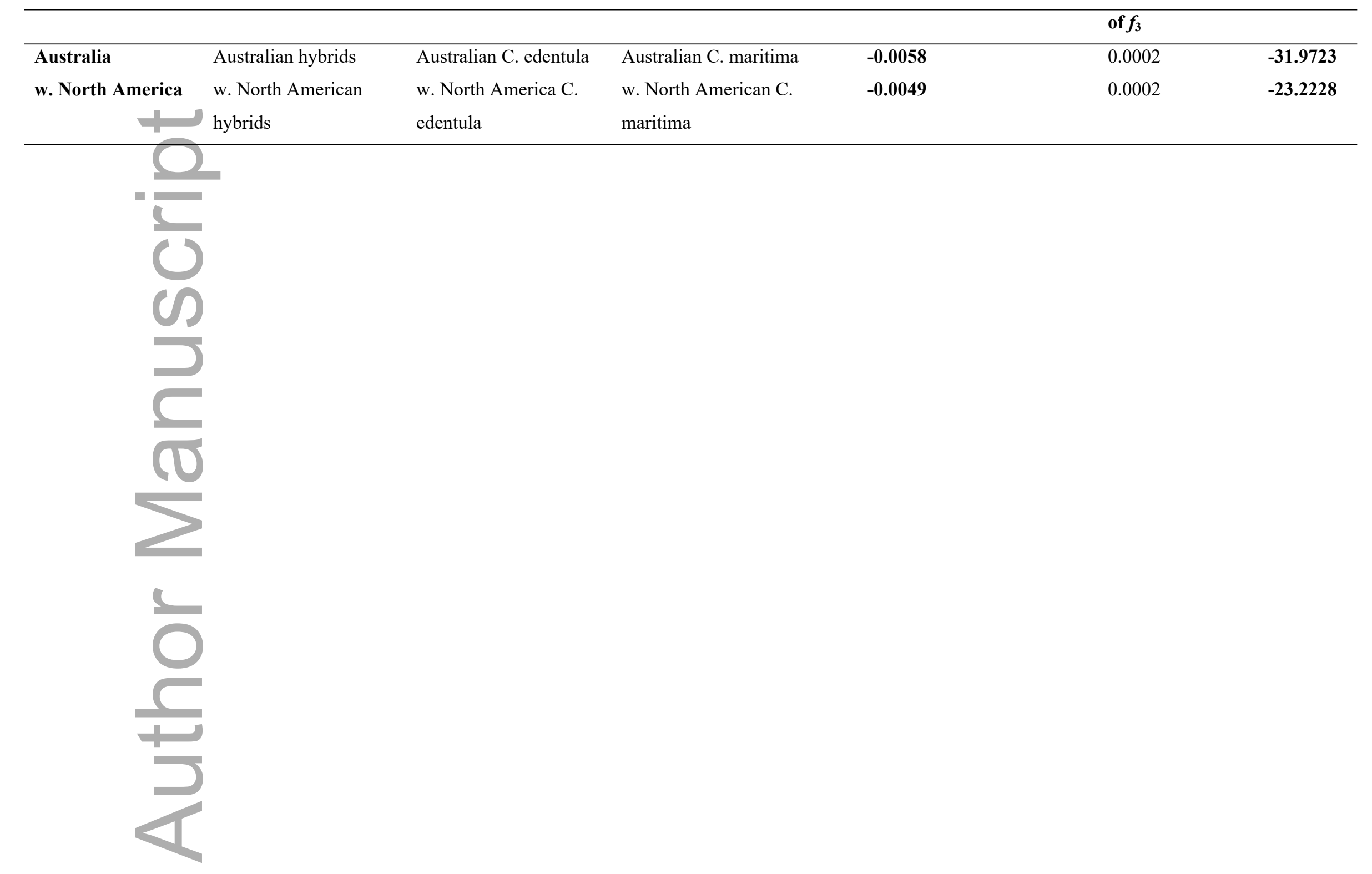

This article is protected by copyright. All rights reserved 


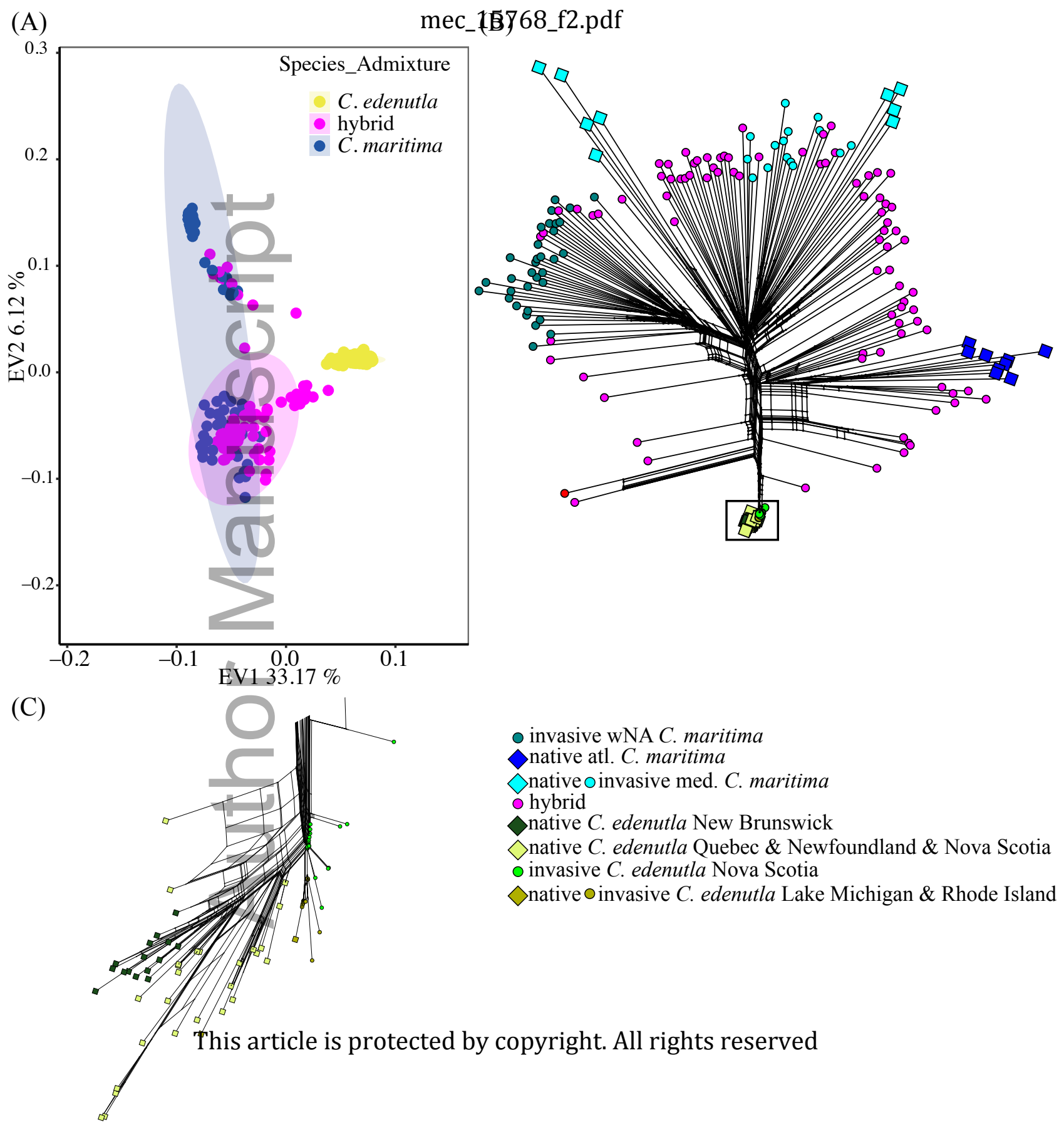




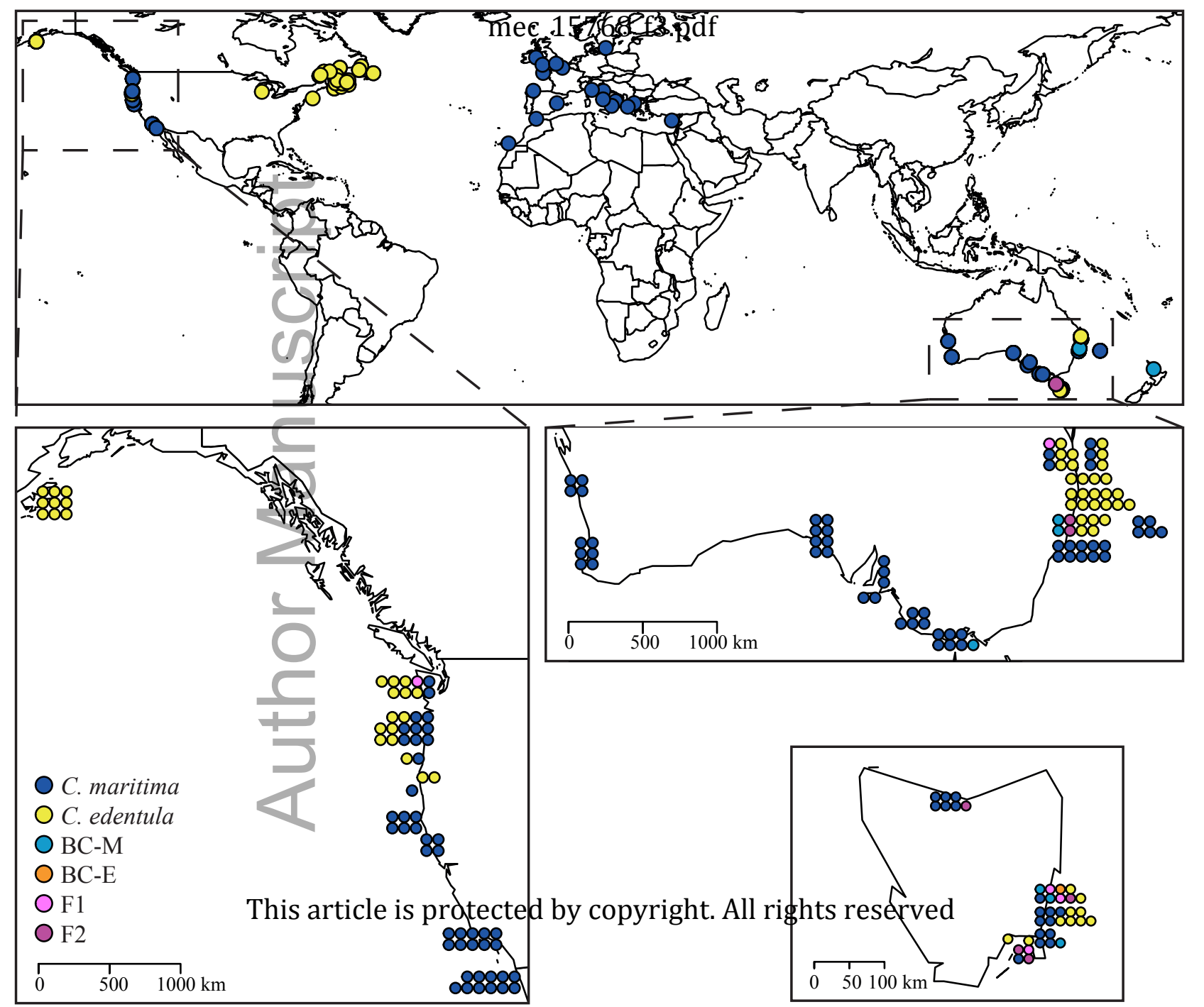


(A)

(B)

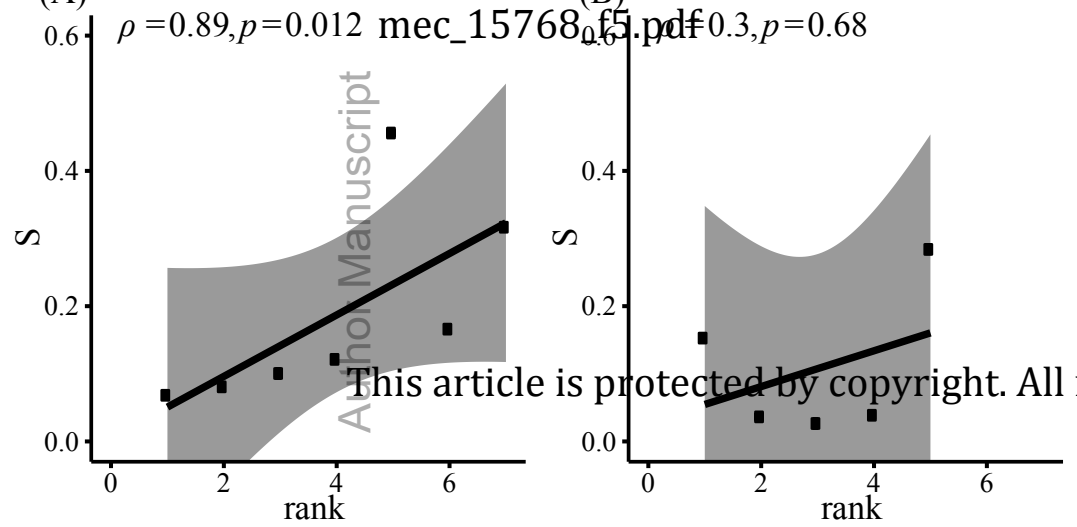




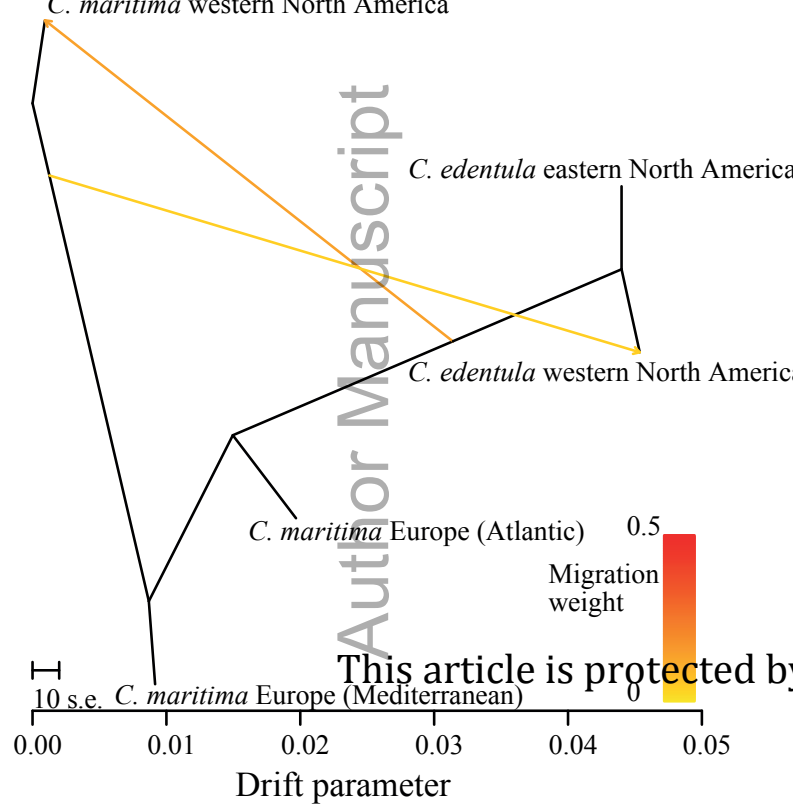

C. maritima Europe (Atlantic)

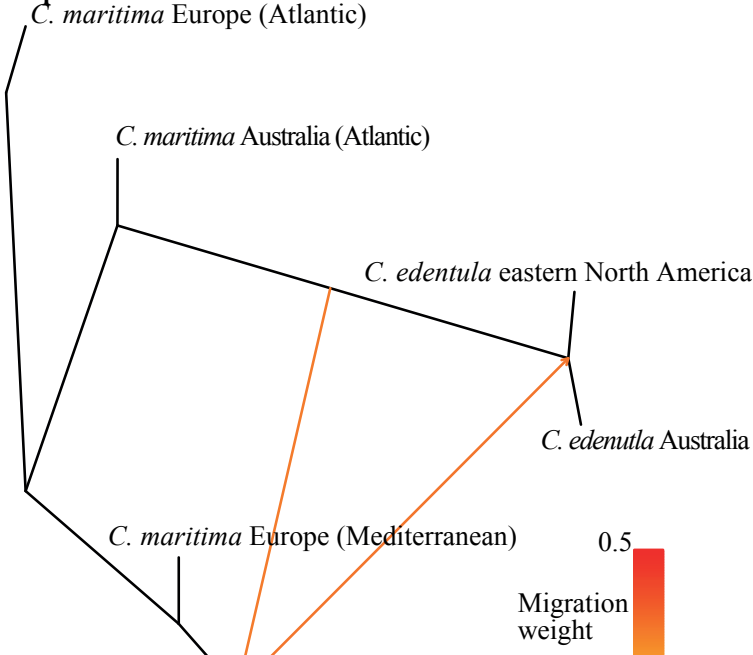
weight

Drift parameter 


\section{University Library}

\section{- M I N E R VA \\ A gateway to Melbourne's research publications}

Minerva Access is the Institutional Repository of The University of Melbourne

\section{Author/s:}

Rosinger, HS;Geraldes, AM;Nurkowski, KA;Battlay, P;Cousens, RD;Rieseberg, LH;Hodgins, KA

Title:

The tip of the iceberg: Genome wide marker analysis reveals hidden hybridization during invasion

Date:

2021-01-23

Citation:

Rosinger, H. S., Geraldes, A. M., Nurkowski, K. A., Battlay, P., Cousens, R. D., Rieseberg, L. H. \& Hodgins, K. A. (2021). The tip of the iceberg: Genome wide marker analysis reveals hidden hybridization during invasion. MOLECULAR ECOLOGY, 30 (3), pp.810-825. https:// doi.org/10.1111/mec.15768.

Persistent Link:

http://hdl.handle.net/11343/298149

License:

CC BY-NC-ND 